*ak RMIS View/Frint Document Cover Sheet tow

This document was retrieved from the Documentation and Records Manaqement (DRM) ISEARCH System. It is intended for Information only and may not be the most recent or updated version. Contact a Document Service Center (see Hanford Info for locations) if you need additional retrieval information.

Accession \#: D196013206

Document \#: SD-TD-ER-005

Title/Desc:

LDUA BASELINE SYS DESCRIPTION

Pages: 45 
2. To: (Receiving Organization) Remote System and Sensor Applications 8 A800

5. Proj./Prog./Dept./Div.: Light Duty Utility Arm

8. Originator Remarks:

Light Duty Utility Arm Baseline System Description
3. From: (Originating Organization) Remote System and Sensor Applications 8 A800

b. Cog. Engr.:

Gary R. Kiebel
4. Related EDT No.:

$N / A$

7. Purchase Order Mo.:

$\mathrm{N} / \mathrm{A}$

9. Equip./Component No.: LDUA/1000

10. System/Bldg./Facility: $4706 / 400$

11. Receiver Renarks:

12. Major Assm. Dwg. No.: $N / A$

13. Permit/Permit Application Ho.: $N / A$

14. Required Response Date: $12 / 15 / 95$

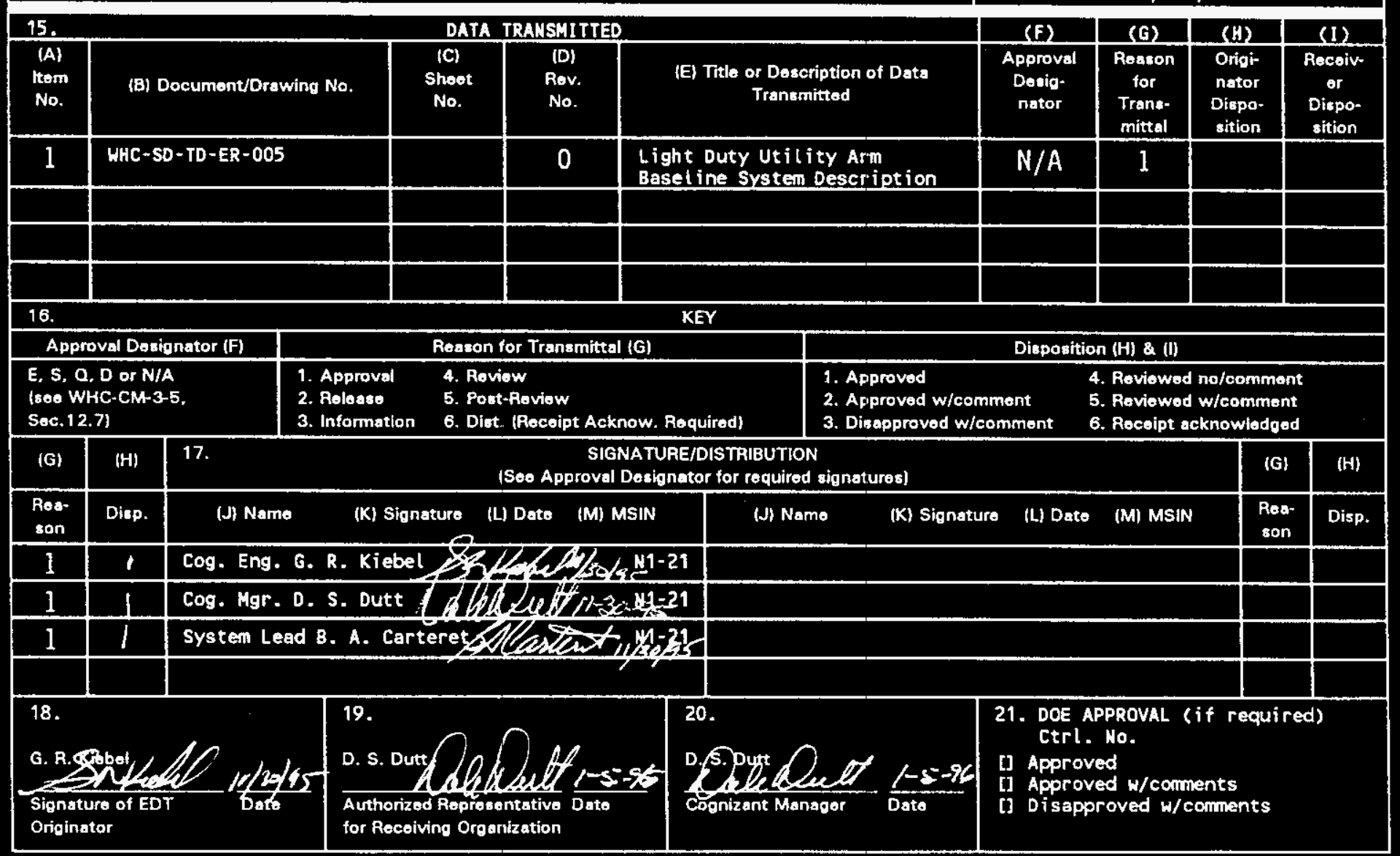

BD-7400-172-2 (04/94) GEF097 


\section{Light Duty Utility Arm Baseline System Description}

Gary R. Kiebel

Westinghouse Hanford Company, Richland, WA 99352

U.S. Department of Energy Contract DE-AC06-87RL10930

EDT/ECN: 140941

Org Code: 8 A800

B\&R Code: EW4010000
UC: 2060

Charge Code: H1EO?

Total Pages: 21 4 48

Key Words: Light Duty Utility Arm (LDUA), Baseline System Description

Abstract: This document describes the configuration of the Light Duty Utility Arm (LDUA) Baseline System. The baseline system is the initial configuration of the LDUA system that will be qualified for hot deployment in Hanford single shell underground storage tanks.

TRADEMARK DISCLAIMER. Reference herein to any specific commercial product, process, or service by trade name, tradenark, manufacturer, or otherwise, does not necessarily constitute or imply its endorsenent, recommendation, or favoring by the United States Government or any agency thereof or its contractors or subcontractors.

Printed in the United States of America. To obtain copies of this document, contact: HHC/8CS Document Control Services, P.0. Box 1970, Mailstop H6-08, Richland HA 99352, Phone (509) 372-2420; Fax (509) 376-4989.
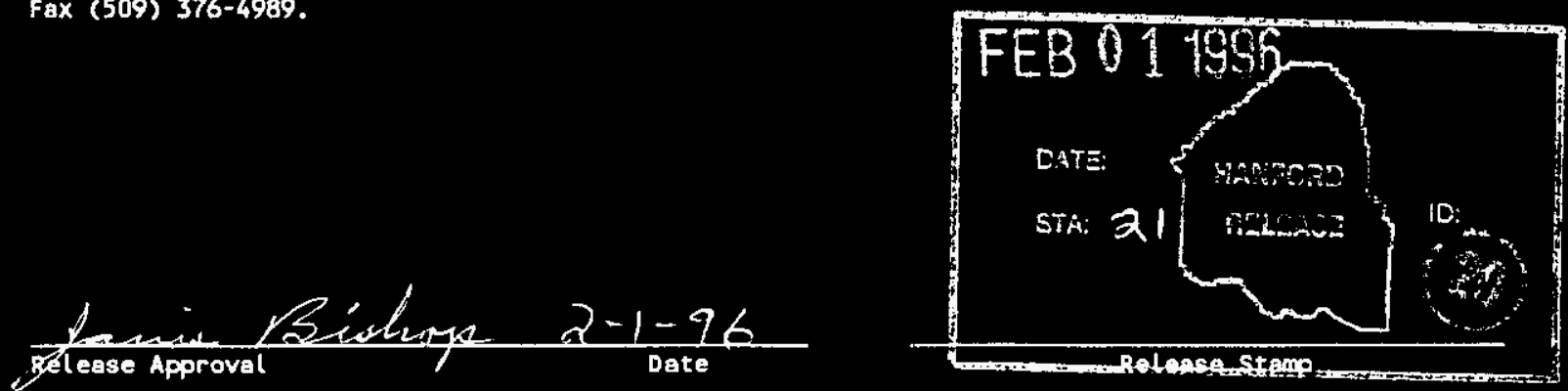
WHC-SD-TD-ER-005, Rev. 0

CONTENTS

LIGHT DUTY UTILITY ARM

BASELINE SYSTEM DESCRIPTION

ABBREVIATIONS, ACRONYMS, AND INITIALISMS $\ldots \ldots \ldots \ldots \ldots \ldots \ldots \ldots$ iii

1.0 INTRODUCTION $\ldots \ldots \ldots \ldots \ldots \ldots \ldots \ldots \ldots \ldots \ldots \ldots \ldots \ldots \ldots \ldots$

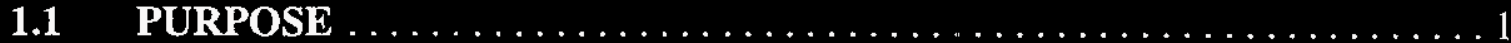

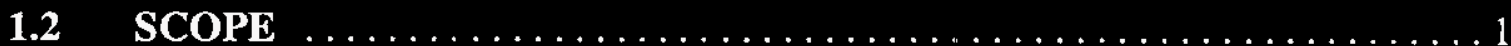

1.3 BACKGROUND $\ldots \ldots \ldots \ldots \ldots \ldots \ldots \ldots \ldots \ldots \ldots \ldots \ldots \ldots$

1.4 OVERVIEW OF LDUA SYSTEM $\ldots \ldots \ldots \ldots \ldots \ldots \ldots \ldots \ldots \ldots$

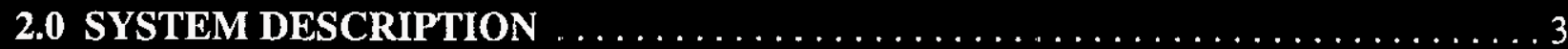

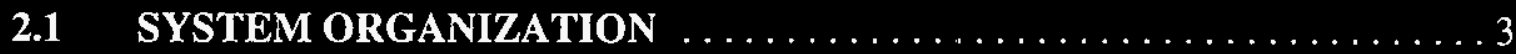

$2.2 \quad$ ARM AND DEPLOYMENT SYSTEM (2000) $\ldots \ldots \ldots \ldots \ldots \ldots \ldots$

2.2.1 Mobile Deployment System (2100) $\ldots \ldots \ldots \ldots \ldots \ldots \ldots \ldots$

2.2.2 Vertical Positioning Mast (2200) $\ldots \ldots \ldots \ldots \ldots \ldots \ldots \ldots$

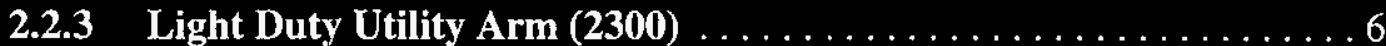

2.2.4 LDUA Subsystem Controller (2400) $\ldots \ldots \ldots \ldots \ldots \ldots \ldots$

2.2.5 Purge System $\ldots \ldots \ldots \ldots \ldots \ldots \ldots \ldots \ldots \ldots \ldots \ldots \ldots$

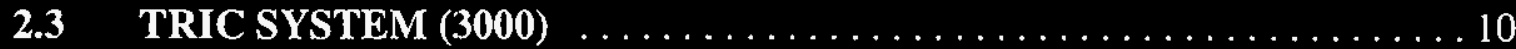

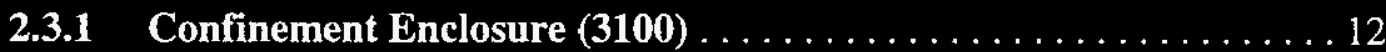

2.3.2 Decontamination System (3300) $\ldots \ldots \ldots \ldots \ldots \ldots \ldots \ldots \ldots \ldots \ldots$

2.3.3 Miscellaneous Instrumentation and Control (3500) $\ldots \ldots \ldots \ldots \ldots$

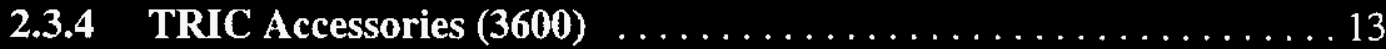

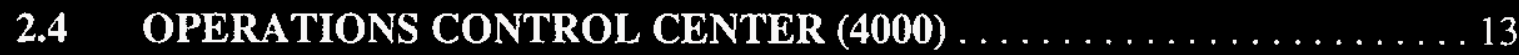

2.4.1 Operations Control Trailer (4100) $\ldots \ldots \ldots \ldots \ldots \ldots \ldots \ldots$

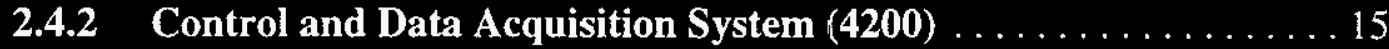

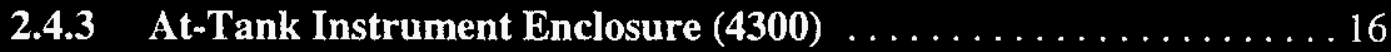

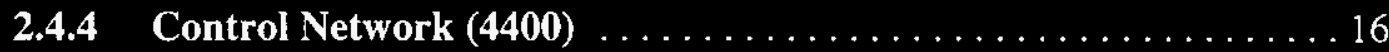

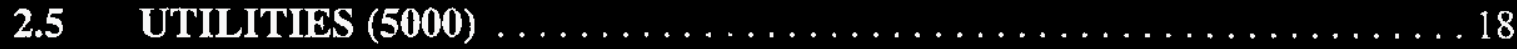

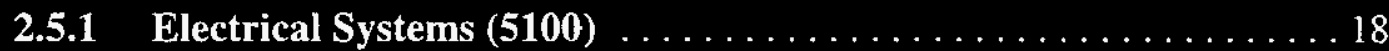

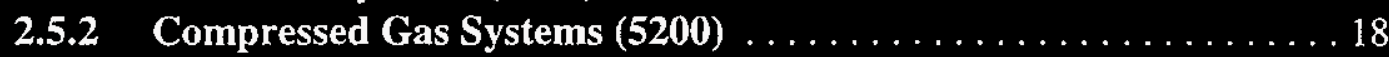

2.5.3 Miscellaneous Gas Systems (5400) . . . . . . . . . . . . . . . 19

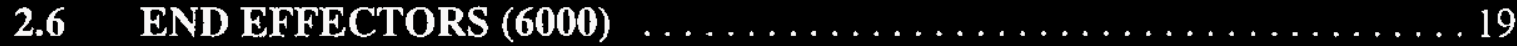

2.6.1 Tank Mapping Systems (6100) $\ldots \ldots \ldots \ldots \ldots \ldots \ldots \ldots \ldots$

2.6.2 Remote Viewing Systems (6200) . . . . . . . . . . . . . . . . 19

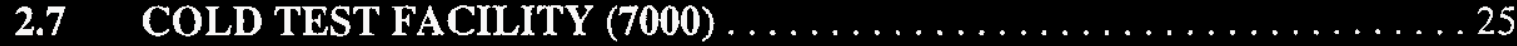

2.8 OTHER EQUIPMENT (8000) $\ldots \ldots \ldots \ldots \ldots \ldots \ldots \ldots \ldots \ldots \ldots \ldots$

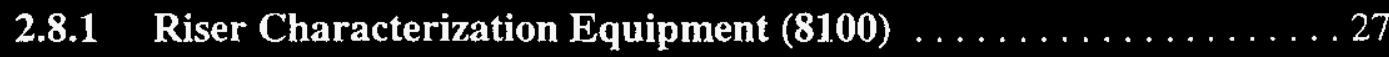

2.8.2 Operations Overview Video System (8200) $\ldots \ldots \ldots \ldots \ldots \ldots . \ldots 27$ 
WHC-SD-TD-ER-005, Rev. 0

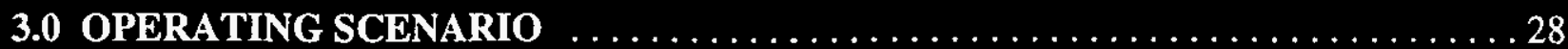

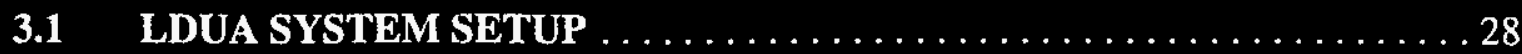

3.2 LDUA SYSTEM OPERATION $\ldots \ldots \ldots \ldots \ldots \ldots \ldots \ldots \ldots \ldots \ldots \ldots \ldots \ldots$

3.3 LDUA SYSTEM TAKEDOWN $\ldots \ldots \ldots \ldots \ldots \ldots \ldots \ldots \ldots \ldots \ldots \ldots$

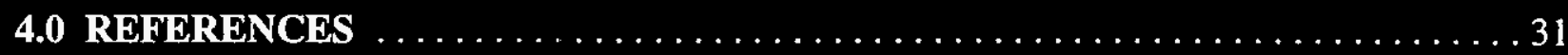

APPENDIX A LDUA SYSTEM BLOCK DIAGRAMS $\ldots \ldots \ldots \ldots \ldots \ldots \ldots$ A 
WHC-SD-TD-ER-005, Rev. 0

\section{ABBREVIATIONS, ACRONYMS, AND INITIALISMS}

$\begin{array}{ll}\text { ASME } & \text { American Society of Mechanical Engineers } \\ \text { ATIE } & \text { At-Tank Instrument Enclosure } \\ \text { CPU } & \text { Central Processor Unit } \\ \text { CTF } & \text { Cold Test Facility } \\ \text { DOE } & \text { U.S. Department of Energy } \\ \text { DOE-RL } & \text { U.S. Department of Energy-Richland Operations } \\ \text { EE } & \text { end effector } \\ \text { EEES } & \text { end effector exchange system } \\ \text { EIA } & \text { Electronic Industrial Association } \\ \text { F\&R } & \text { Functions, Requirements \& Assumptions } \\ \text { HLAN } & \text { Hanford Local Area Network } \\ \text { HRSVS } & \text { High Resolution Stereo Video System } \\ \text { HVAC } & \text { Heating, Ventilation, and Air Conditioning } \\ \text { LDUA } & \text { Light-Duty Utility Arm } \\ \text { MDS } & \text { Mobile Deployment System } \\ \text { MDS } & \text { Mobile Deployment System } \\ \text { NEC } & \text { National Electric Code } \\ \text { OAS } & \text { Optical Alignment Scope } \\ \text { ORR } & \text { Operational Readiness Review } \\ \text { OSVS } & \text { Overview Stereo Video System } \\ \text { OVS } & \text { Overview Video System } \\ \text { PDS } & \text { Power Distribution Skid } \\ \text { SCADAS } & \text { supervisory control and data acquisition system } \\ \text { SCS } & \text { Supervisory Control System } \\ \text { SDAS } & \text { Supervisory Data Acquisition System } \\ \text { SSPS } & \text { Still/Stereo Photo System } \\ \text { SST } & \text { single-shell tank } \\ \text { TFA } & \text { Tank Focus Area } \\ \text { TIP } & \text { Tool Interface Plate } \\ \text { TMS } & \text { Topographical Mapping System } \\ \text { TRIC } & \text { Tank Riser Interface Confinement System } \\ \text { VAC } & \text { Volts, Alternating Current } \\ \text { VME } & \text { Versa Module Eurocard } \\ \text { VPM } & \text { Vertical Positioning Mast } \\ \text { WHC } & \text { Westinghouse Hanford Company } \\ & \\ \end{array}$




\section{WHC-SD-TD-ER-005, Rev. 0 \\ LIGHT DUTY UTILITY ARM \\ BASELINE SYSTEM DESCRIPTION}

\subsection{INTRODUCTION}

\subsection{PURPOSE}

This document describes the configuration of the Light Duty Utility Arm (LDUA) Baseline System. The baseline system is the initial configuration of the LDUA System that will be qualified for hot deployment in Hanford single shell underground storage tanks.

\subsection{SCOPE}

This document shall be the basis for planning the LDUA qualification testing.

\subsection{BACKGROUND}

The LDUA program was initiated in 1992 by the Department of Energy's (DOE) Office of Science and Technology (then known as the Office of Technology Development) at the request of Hanford Tank Waste Remediation Systems (TWRS) as a development effort to provide a new capability to obtain information and support operations associated with underground storage tanks, and to aid in the remediation of those tanks at Hanford and throughout the DOE complex.

\subsection{OVERVIEW OF LDUA SYSTEM}

The LDUA System deploys a family of tools and sensors, called end effectors, into underground storage tanks by means of a robotic arm on the end of a telescoping mast, and collects and manages the data that they generate. Access into the tank is gained through existing risers. A Mobile Deployment Subsystem transports the mast and arm between tanks and positions them over a $30.5 \mathrm{~cm}$ (12in) tank riser for deployment. Ancillary subsystems support the main deployment equipment, performing such functions as: maintaining confinement of the tank atmosphere; decontamination of mast, arm, and end effector; power distribution; and observation of in-tank operations. The LDUA system is operated from the remote Operations Control Trailer located outside the perimeter fence of the tank farm, up to $275 \mathrm{~m}$ ( $900-\mathrm{ft}$ ) from the deployment vehicle (see Figure 1-1). 
WHC-SD-TD-ER-005, Rev. 0

Figure 1-1, Light-Duty Utility Arm System.

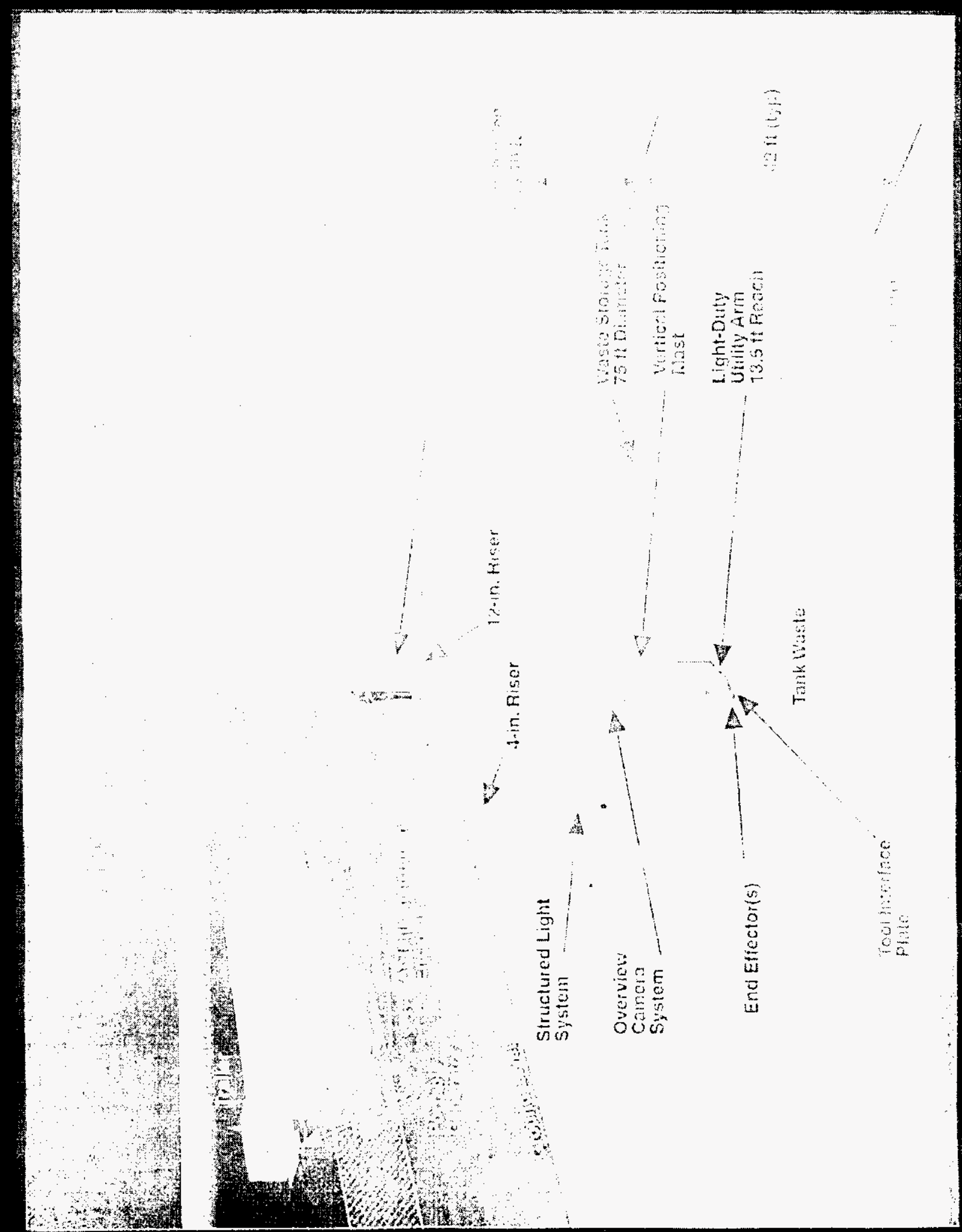


WHC-SD-TD-ER-005, Rev. 0

The LDUA System provides the capability to reach locations within the tank and waste surface that are not directly under the access risers. This capability has not been available to tank farm operations before and is one of the primary reasons that the LDUA System was developed. The LDUA System is designed to operate safely in the hazardous (high radiation, flammable gasses, corrosive chemicals) environment of underground storage tanks at the Hanford site as well as underground storage tanks located at other DOE sites. It is also designed to accept new end effectors and adapt to new missions with little disruption to the existing system.

\subsection{SYSTEM DESCRIPTION}

\subsection{SYSTEM ORGANIZATION}

The LDUA System is organized into a hierarchy of major equipment systems and subsystems. A hierarchical numbering scheme is used to identify them:

2000 Arm/Deployment System

2100 Mobile Deployment System (MDS)

2200 Vertical Positioning Mast (VPM)

2300 Light Duty Utility Arm (LDUA)

2310 Tool Interface Plate (TP)

2400 LDUA Subsystem Controller

3000 Tank Riser Interface and Confinement (TRIC) System

3100 Confinement Enclosure

3300 Decontamination System

3500 Miscellaneous TRIC Instrumentation and Control

3600 TRIC Accessories

4000 Operations Control Center (OCC)

4100 Operations Control Trailer (OCT)

4200 Supervisory Control and Data Acquisition System (SCADAS)

4300 At-Tank Instrument Enclosure (ATIE)

4400 Control Network

5000 Utilities

5100 Electrical Systems

5110 Temporary Substation

5120 Portable Generator

5130 Power Distribution Skid

5200 Compressed Gas Systems

5230 Purge Air Supply

5400 Miscellaneous Gas Systems

5410 Purge Gas Supply 
WHC-SD-TD-ER-005, Rev. 0

6000 End Effectors

6100 Tank Mapping Systems

6110 Topographical Mapping System

6200 Remote Viewing Systems

6210 Overview Video System

6220 Overview Stereo Video System

6230 High Resolution Stereo Video System

6240 Still/Stereo Photo System

6250 Optical Alignment Scope

7000 Cold Test Facility

8000 Other Equipment

8100 Riser Characterization Equipment

8200 Operations Overview Video System

\subsection{ARM AND DEPLOYMENT SYSTEM (2000)}

\subsubsection{Mobile Deployment System (2100)}

The Mobile Deployment System (MDS) is used to transport the LDUA between and within tank farms for deployment (see Figure 2-1). It is based on a single axle flatbed truck with a $4.8 \mathrm{~m}(16 \mathrm{ft})$ wheelbase and an overall length of less than $7.6 \mathrm{~m}$ (25ft). The truck has outriggers which extend and lock to provide a firm base for deployment into the tank. The MDS is equipped with the X-Y-Roll Table that allows the Vertical Positioning Mast (VPM) housing to be elevated to the vertical position for deployment and lowered to the horizontal position for transport. The VPM housing is $10.7 \mathrm{~m}$ (35ft) long. The X-Y-Roll Table also provides fine positioning control of the $X$ and $Y$ axes of translation over a range of $15 \mathrm{~cm}(6 \mathrm{in})$, and the pitch and roll axes over a range of plus or minus 5 degrees. These fine control motions are used to align the VPM with the riser to assure free passage of the VPM into the tank. The positioning table axes have mechanical locks that can be set to prevent slippage once final position has been achieved. The VPM housing has electronic inclinometers that can detect any ground settling or other unwanted motion that may affect the alignment of the VPM to the riser.

\subsubsection{Vertical Positioning Mast (2200)}

The Vertical Positioning Mast (VPM) provides the gross vertical positioning of the LDUA within the waste tank. When fully deployed, the VPM can reach $14 \mathrm{~m}(47 \mathrm{ft})$ below the bottom of the VPM housing (measured at the shoulder pitch joint of the LDUA). This means that the end effector can reach the bottom of the deepest Hanford single shell tank (nominally $15 \mathrm{~m}$ (50ft) below grade). The VPM is supported by a truss frame constructed of 6061-T6 aluminum box tubing. This frame is covered by aluminum panels to form a housing that provides a sealed contamination boundary in both the deployed and transport modes. The VPM housing has a standard $35 \mathrm{~cm}$ (14in) gate valve at the bottom which is remotely operated to seal the housing or to allow the VPM and LDUA to emerge. 
WHC-SD-TD-ER-005, Rev. 0

Figure 2-1. Mobile Deployment System.

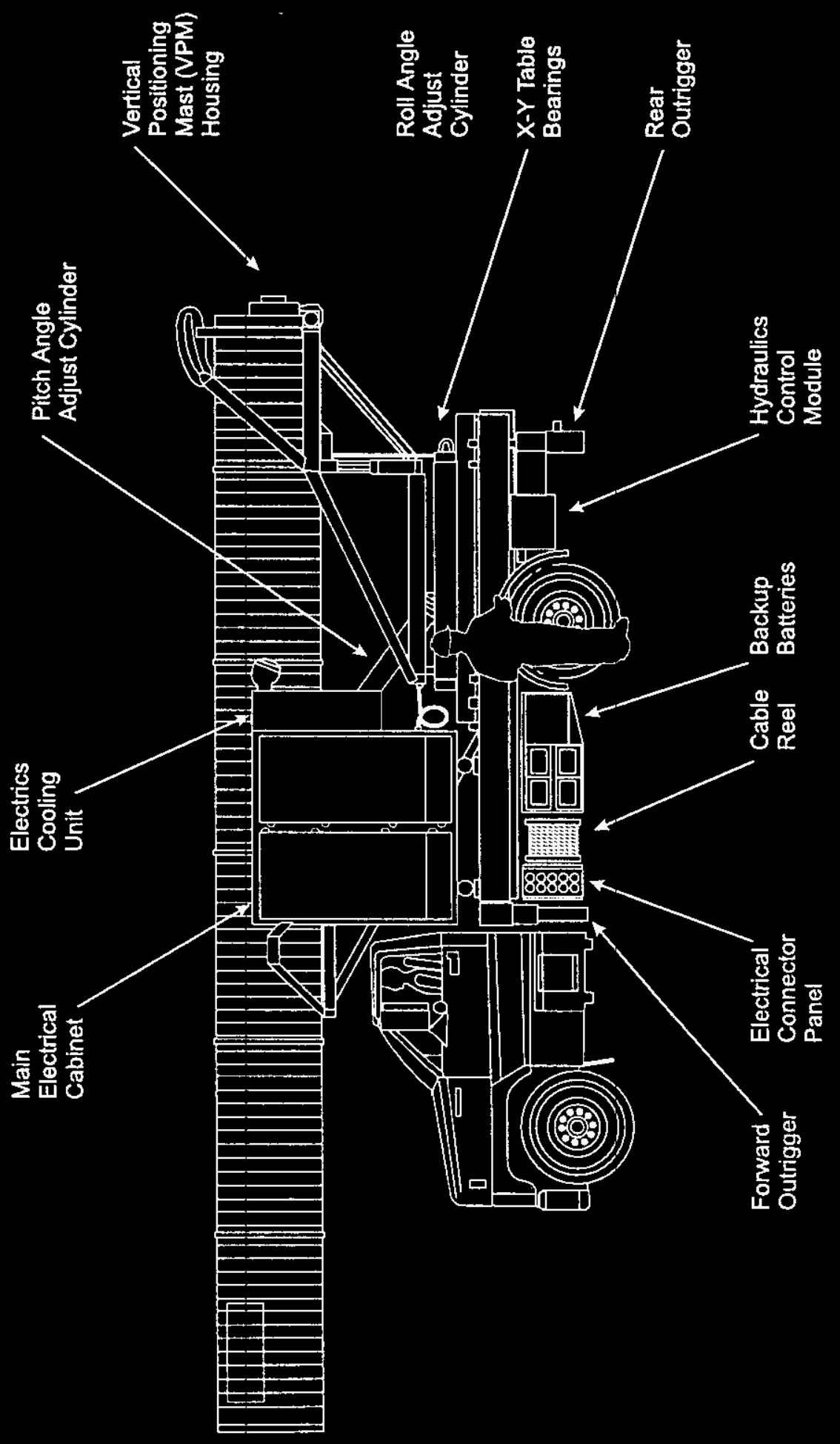




\section{WHC-SD-TD-ER-005, Rev. 0}

The VPM has two telescoping tubular sections. The LDUA is attached to the bottom of the inner VPM tube and both are wholly contained inside the outer VPM tube when fully retracted. Each tube is driven by a hydraulic winch through a pair of steel cables (for redundancy). The winches are equipped with fail-safe brakes. The position of each tube is accurately sensed by resolvers that are actuated by small cables attached to the tubes. The VPM can move with an accuracy of $13 \mathrm{~mm}(0.5 \mathrm{in})$ and the ability to return to a given position within $5 \mathrm{~mm}(0.2 \mathrm{in})$. The resolvers provide a resolution of better then $1.3 \mathrm{~mm}(0.05 \mathrm{in})$.

The VPM tubes are made of 304L stainless steel. The outer VPM tube is carried on linear ball bearings that travel on rails mounted on a large member of the aluminum truss frame. The rails are accurately aligned to provide smooth motion of the VPM with negligible runout. The inner VPM tube is carried on a set of rollers that travel on the inside diameter of the outer VPM tube. The VPM has infinitely variable speed control from zero to $4.6 \mathrm{~m}$ (15ft) per minute.

The LDUA control system permits selection of the sequence of motion of the VPM tube sections - e.g. Outer tube moves first or inner tube moves first. Outer tube first mode protects the LDUA during transit through the riser, but inner tube first mode allows best coverage of decontamination spray.

\subsubsection{Light Duty Utility Arm (2300)}

The Light Duty Utility Arm (LDUA) is a robotic manipulator that has seven degrees of freedom that provide dexterity to reach around obstructions in the tank while orientating and positioning end effectors to any surface within its operating envelope (see Figure 2-2). The operating envelope of the LDUA extends out to $2.8 \mathrm{~m}(9 \mathrm{ft})$ from the centerline of the VPM. The LDUA has a maximum reach of $4.1 \mathrm{~m}$ (13.5ft) (shoulder to wrist) when fully extended. It can deploy into a tank with as little as $1.8 \mathrm{~m}(6 \mathrm{ft})$ of clearance between the bottom of the riser and the surface of the waste. Five of the joints of the LDUA are hydraulically actuated and two (wrist roll and shoulder yaw) are electrically actuated. All joints are equipped with brakes. A backup battery power supply provides up to four hours of brake actuation in the event that main power to the LDUA System is lost. If all power to the LDUA is removed, its joints will slowly relax (limp mode) allowing it to be recovered through the riser.

The maximum payload of the LDUA is $34 \mathrm{~kg}(75 \mathrm{lb})$, with a moment loading of $113 \mathrm{~N}-\mathrm{m}$ (1000in-lb) at the TIP mating surface and $17 \mathrm{~N}-\mathrm{m}(150 \mathrm{in}-\mathrm{lb})$ moment about the wrist roll axis. At the nominal payload of $23 \mathrm{~kg}(50 \mathrm{lb})$, the LDUA is designed to have a repeatability of plus or minus $5 \mathrm{~mm}(0.2 \mathrm{in})$ from an established starting point and a positional error of plus or minus $13 \mathrm{~mm}(0.5 \mathrm{in})$. The LDUA Controller is designed to compensate for static deflection of the VPM under load in order to minimize the end-to-end error of the whole system. The LDUA is equipped with resolvers on all of its joints that provide a resolution of better than $1.3 \mathrm{~mm}$ (0.05in). The LDUA is constructed almost entirely of $17-4 \mathrm{PH}$ stainless steel which provides high strength and corrosion resistance. It is a completely sealed unit that carries all of its utilities internally and it has flexible boots at each joint to maintain the seal. There is a video camera and lights in the shoulder section of the LDUA that can pan and tilt to observe most of the working envelope. 
WHC-SD-TD-ER-005, Rev. 0

Figure 2-2. Light-Duty Utility Arm.

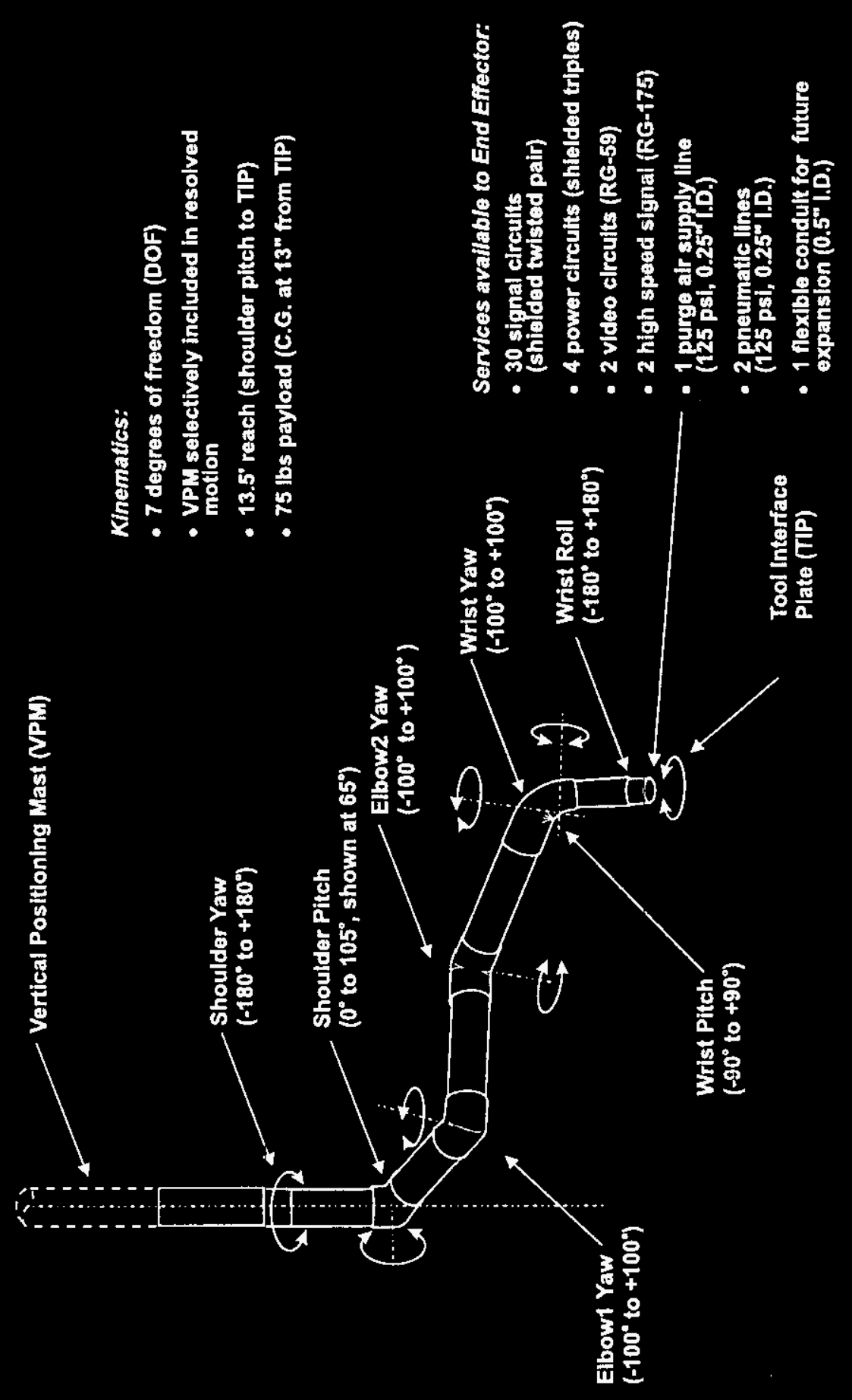


The LDUA has a Tool Interface Plate (TIP) (2310) at its wrist for mounting end effectors. The TIP provides a standard mounting surface common to each of the LDUA deployed end effectors that are used in the underground storage tanks. It consists of two plates, with the master plate located on the wrist of the LDUA, and the slave plate located on the end effector. The interface between the plates is sealed against the tank atmosphere and contents. The TIP has a set of guide pins that assure proper alignment of the two TIP plates and there are three mechanical latches that positively engage and lock the TIP halves together. A set of electrical and pneumatic utility services are provided for end effector operation. These are carried through the TIP by connectors within the sealed interior of the TIP. These utility services includes 30 shielded twisted pairs (for signals), 4 shielded triples (for power), 4 coaxial cables (for video or other high-speed signals), one dedicated hose (for supplying purge air to end effectors), and 2 general purpose hoses (for pneumatics). The utility services are carried to the ATIE where they are available to the end effector's support equipment. A six axis force/torque sensor is provided in the LDUA's wrist joint. It is not presently integrated into the control system, but is available for future applications.

\subsubsection{LDUA Subsystem Controller (2400)}

The LDUA Subsystem Controller provides several modes of control for the LDUA and VPM. It allows the operator to control each joint of the LDUA and VPM individually. It also provides resolved motion, which is the ability to position and orient the end effector with respect to a Cartesian coordinate system (x,y, $\mathrm{z}$, roll, pitch, yaw). The VPM can be selectively included in or excluded from resolved motions. Motion can be directed both by teleoperation (human-in-the-loop) using rate-input joysticks or by entering numerical coordinates into the LDUA Console. The LDUA Subsystem Controller also controls the MDS, including the X-YRoll Table.

The Subsystem Controller is based on the Versa Module Eurocard (VME) industry standard computer instrumentation bus. It is a multi-processor (CPU) design. The main CPU (called the Arm Level Controller or ALC) processes operator commands, calculates joint trajectories, directs the joint servo control boards, and monitors and controls individual sensors and actuators (such as the VPM inclinometers and the LDUA joint brakes). The servo control boards for the LDUA, VPM, and MDS X-Y-Roll Table joints are each highly intelligent special purpose computerized modules that control the primary feedback loop for each joint. The GISC CPU supports the interface between the LDUA Controller and the Supervisory Control System.

\subsubsection{Purge System}

The LDUA System is purged by a constant low flow of instrument grade (clean, low moisture) air. This purge flow enables the LDUA System to meet National Electric Code requirements for operation in Class 1, Division 1, Group B flammable atmospheres by maintaining the internal pressure of the end effector, LDUA, and VPM above the pressure of the tank atmosphere (see Figure 2-3). This pressure differential also keeps the interior surfaces of these components clean and uncontaminated by preventing in-leakage of tank atmosphere. 
WHC-SD-TD-ER-005, Rev. 0

Figure 2-3. LDUA Purging Schematic.

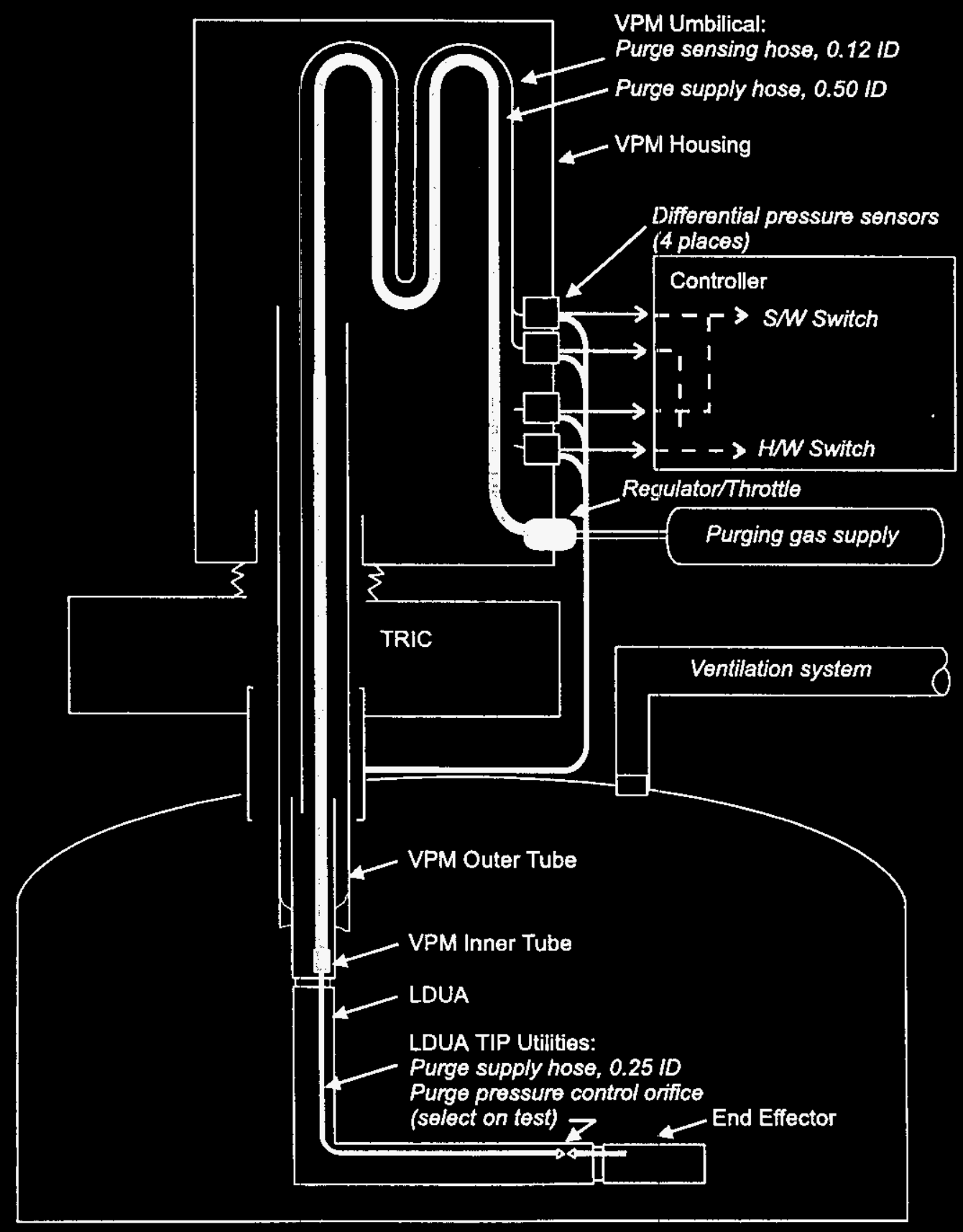


Purge air is supplied by the Purge Air Supply subsystem (see section 2.5.2) and carried by hose to a quick disconnect fitting on the VPM housing. At this point, the purge air pressure is regulated to $414 \mathrm{kPa}(60 \mathrm{psi})$. The purge air is carried by hose through the VPM, LDUA, and TIP into the end effector. The purge air is released in the end effector and flows through it into the LDUA via vent openings provided in the TIP. The purge flow continues through the whole length of the LDUA and into the inner and then outer VPM tubes. From the outer VPM tube, it passes into the VPM housing from where it is exhausted into the TRIC.

Differential pressure sensors monitor the purge pressure in the inner VPM tube and the VPM housing (same as the outer VPM tube). These sensors are referenced to the tank pressure by a pressure tap below the Riser Isolation Valve (see section 2.3.2). The purge system is designed to maintain a pressure differential in the LDUA of 620Pa (2.5in-water) above tank pressure and $470 \mathrm{~Pa}$ (1.9in-water) in the VPM outer tube and VPM housing. An alarm is generated if the pressure falls below $62 \mathrm{~Pa}(0.25 \mathrm{in}$-water $)$, which is comfortably above the minimum of $25 \mathrm{~Pa}(0.1$ in-water) that is required by the NEC. The LDUA Controller can operate in a mode where it will automatically remove all electrical power from the inside of the VPM, LDUA, and end effector. This mode can be selectively enabled by the operator, and it is required when operating in tanks with flarnmable atmospheres in order to meet NEC requirements.

\subsection{TRIC SYSTEM (3000)}

The Tank Riser Interface and Confinement (TRIC) provides an interface between the LDUA system and the waste tank riser (see Figure 2-4). It is used for change-out of end effectors, minor maintenance tasks, and containment of the tank atmosphere. A decontamination system is provided for routine cleaning of the VPM, LDUA, and end effectors to levels acceptable for transportation within the Hanford site. The particular configuration of TRIC used for the Baseline LDUA System is defined as subsystem 3700, or Tank Riser Interface and Confinement with Local Interactive Tool Exchange (TRIC LITE). In this document, the shorter acronym "TRIC" will be used to mean "TRIC LITE". The TRIC is a very simple design which is light enough to bolt directly to the deployment riser. This makes it self-aligning and eliminates the need for adjustments. 
WHC-SD-TD-ER-005, Rev. 0

Figure 2-4. Tank Riser Interface and Confinement (TRIC).

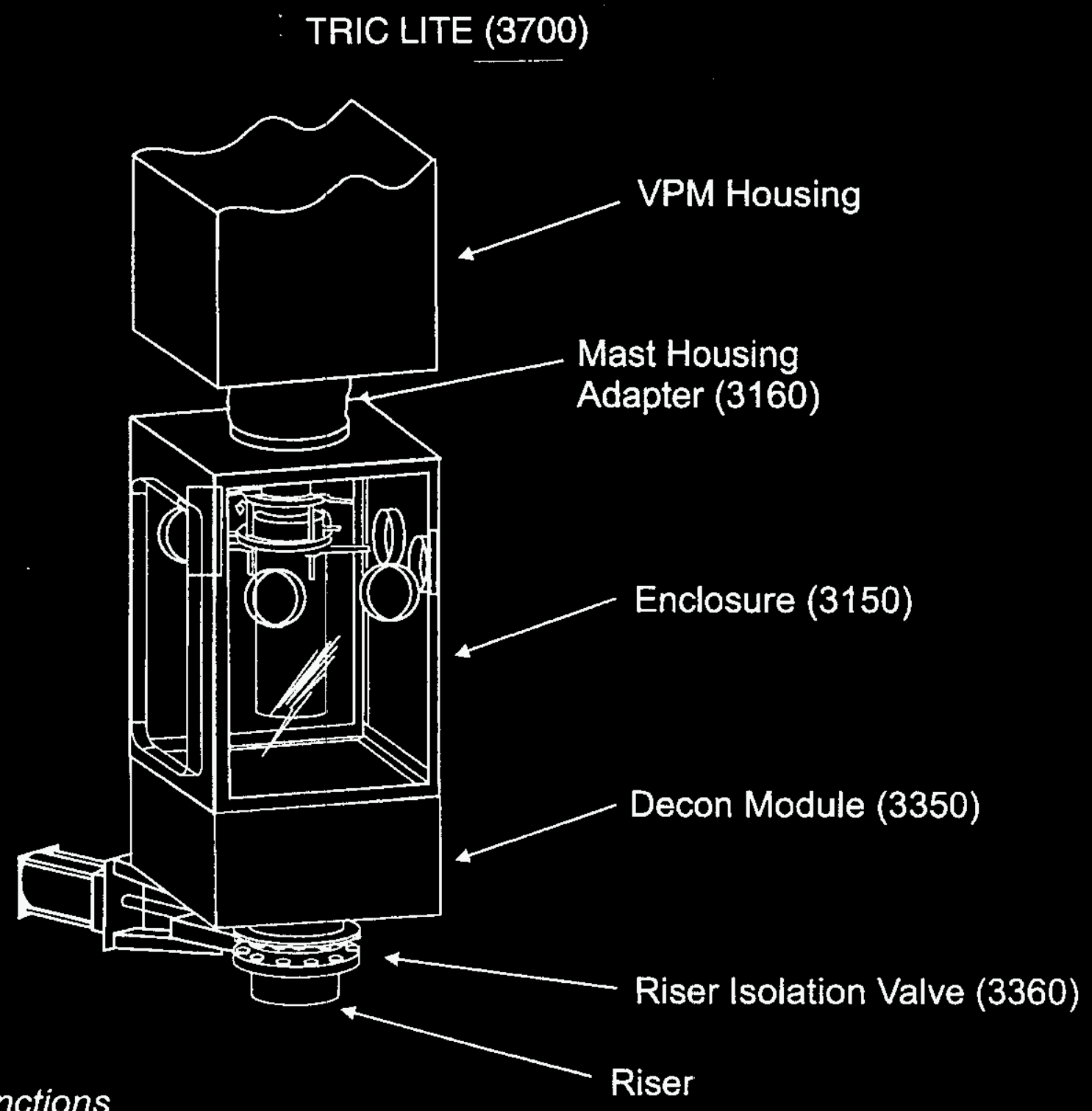

\section{Functions}

-Confine tank atmosphere

-Exchange End Effectors

-Isolate tank atmosphers (valve)

-Decontaminate VPM, LDUA, and End Effector 


\subsubsection{Confinement Enclosure (3100)}

The TRIC Confinement Enclosure (3150) provides radiological confinement when the access riser is open, such as when the LDUA is deployed into the tank. The sides of the Confinement Enclosure are transparent and several sets of gloveports are provided to allow minor hands-on activities to be performed on the LDUA or the end effector. A large door on the side of the enclosure provides access for the exchange of end effectors on the LDUA.

The Mast Housing Adapter (3160) provides a flexible sealed coupling between the top of the confinement enclosure and the bottom of the VPM Housing. Flexibility is necessary to compensate for the differences in riser elevations and different ground surface contours. Flexibility is also necessary to allow for the movement of the VPM Housing during the process of aligning it to the riser.

The enclosure is ventilated by an exhauster connected to another riser of the tank. This maintains a slight negative pressure within the tank to assure that contamination and potentially flammable gases from the tank do not enter the TRIC. A small HEPA filter is provided on the TRIC through which fresh air can be drawn. The exhauster is considered part of the tank farm equipment and not part of the LDUA System.

\subsubsection{Decontamination System (3300)}

The Water Decon Module (3350) provides for removal of external contamination from the VPM, LDUA, and end effector by spraying high pressure water at up to $3.45 \mathrm{MPa}(500 \mathrm{psi})$ at $5.7 \mathrm{~L} / \mathrm{min}(1.5 \mathrm{gal} / \mathrm{min})$ onto them as they are withdrawn from the tank. This module normally remains attached to the bottom of the confinement enclosure. The Riser Isolation Valve (3360) mounts between the riser and the Decon Module. It has a quick-disconnect joint which simplifies installation of the TRIC onto the riser. The valve is separable from the TRIC and is installed first onto the riser flange. Once the valve is secured to the riser flange, the TRIC is moved into position and locked into place with the quick-disconnect joint.

The Decon Module provides a sealed chamber which contains a spray ring that provides 360 degree coverage of the outer surface of the portion of the VPM, LDUA, or end effector that is inside the module. Water and dislodged contamination return to the tank via the riser. A flexible splash barrier is provided between the Decon Module and the Confinement Enclosure to prevent contaminated spray from entering. This splash barrier can be manually tilted up to allow a clear line of sight into the riser for the Optical Alignment Scope (OAS) (see Section 2.6.2.5) during the VPM alignment process. The Decon Water Supply System (3340) supplies pressurized water to the Water Decon Module via a hose that is attached by a double-end shutoff quick-disconnect fitting. The Water Supply System is trailer mounted and has a 1900L (500gal) storage tank (to limit the amount of water added to the tank), and a pump. Electrical heating is provided for freeze protection. Decontamination spray is remotely controlled and monitored via an umbilical cable to the ATIE. 


\subsubsection{Miscellaneous Instrumentation and Control (3500)}

A radiation monitor subsystem (3520) is provided that is sensitive to the gross gamma radiation levels within the Decon Module. It provides a first order check on the effectiveness of the decontamination process. Four Geiger-Mueller (GM) tube type detectors are installed in shield assemblies in four detector wells in the Decon Module. The shield assemblies provide windows that face toward the center of the module. Altogether, the detector/shield array provides 360 degree coverage of the outer surface of the LDUA, VPM, or end effector that is inside the Decon Module. The readout electronics for the detectors are housed in the ATIE.

\subsubsection{TRIC Accessories (3600)}

The Manual End Effector Exchange System (MEEES) (3660) assists the operator in mounting and dismounting end effectors to and from the LDUA. It has a handling fixture which engages indentations on the end effector half of the Tool Interface Plate (TIP) and a lifting and translating mechanism to raise the handling fixture to the level of the LDUA wrist and move it into alignment with the LDUA half of the TIP. The access door in the Confinement Enclosure (3150) is opened to provide access to the LDUA after the Riser Isolation Valve (3360) has been closed to isolate the TRIC from the tank atmosphere. When the handling fixture is close enough to the LDUA wrist, the operator maneuvers it to engage indentations on the LDUA half of the TIP. The operator then uses the handling fixture to pull the two TIP halves tightly together. The TIP halves are then clamped together by means of the three latching mechanisms on the EE half of the TIP which are each secured by the operator rotating a locking cam one-half turn (using a tool with a standard $12.7 \mathrm{~mm}(0.5 \mathrm{in})$ square socket drive). The handling fixture is then disengaged, the door is closed, and the valve is opened allowing the LDUA to deploy into the tank. Dismounting an EE is essentially the reverse process from mounting it.

\subsection{OPERATIONS CONTROL CENTER (4000)}

The Operations Control Center encompasses almost all of the control and data acquisition equipment for the LDUA system. It houses and interconnects the equipment and provides the interfaces for personnel to operate the LDUA integrated systern. It consists of the Operations and Control Trailer (OCT), the At-Tank Instrument Enclosure (ATIE), the Supervisory Control and Data Acquisition System (SCADAS), and the Control Network.

\subsubsection{Operations Control Trailer (4100)}

The Operations Control 'Trailer (OCT) is a $14.6 \mathrm{~m}$ (48ft) standard semi-trailer that is towed to the tank farm and parked outside the perimeter fence (see Figure 2-5). The OCT has an air suspension system to provide a smooth ride for the equipment it houses, and it is fitted with jacks to level and stabilize it when parked. The OCT has thermostatically controlled forced air heating, ventilation and air conditioning (HVAC) system. It is powered from a $480 \mathrm{VAC}$ supply (see section 2.5.1) and it has a complete power distribution system to supply its own lighting and HVAC needs, and to provide $110 \mathrm{VAC}$ power to the electronic equipment that it houses. The OCT has 5 Standard Electronic Industrial Association (ELA) $48 \mathrm{~cm}$ (19in) instrument racks for the mounting of end effector support equipment. The interior of the OCT is fully carpeted on both the walls and floor in order to control noise, static electricity, and dust. The layout of the OCT 


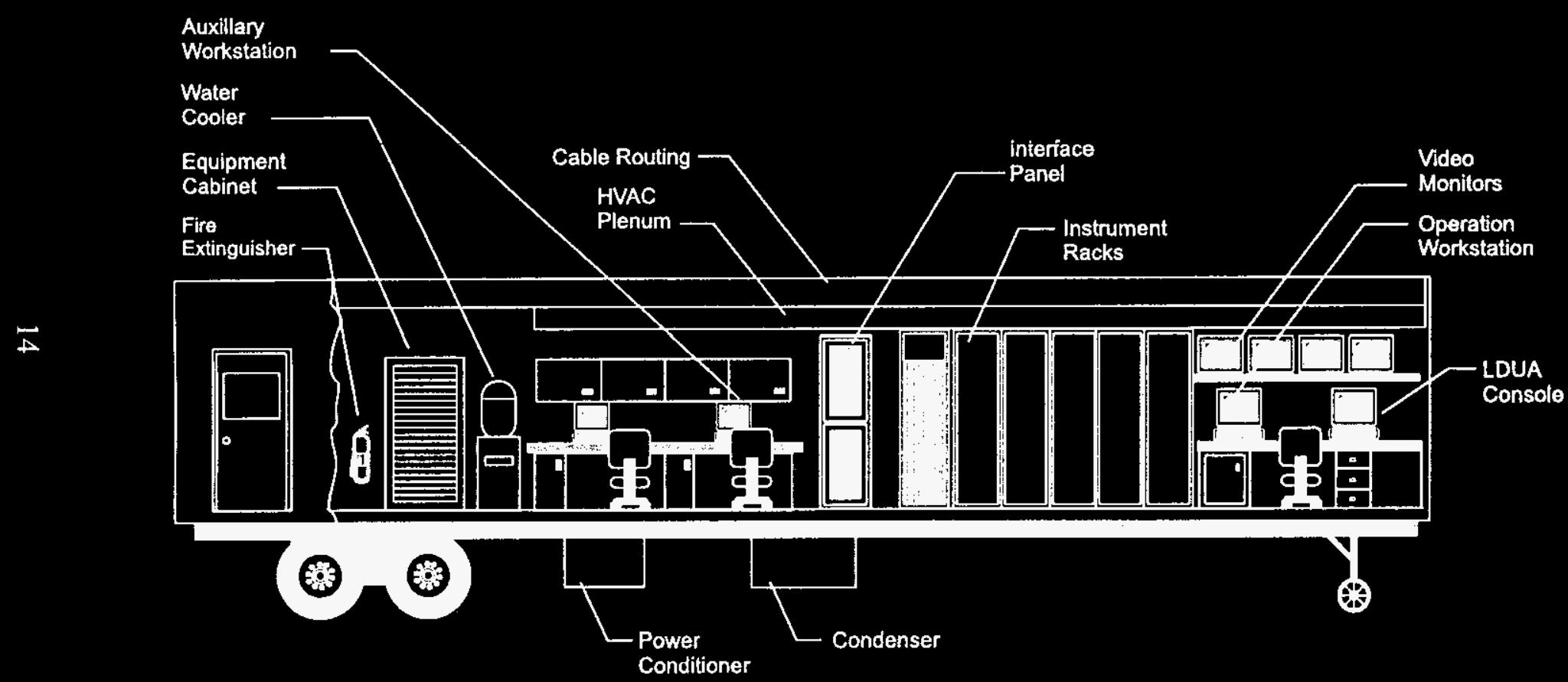

3
0
0
0
1
0
0
0
0
0
0
0
0
0
5
0
9
0
0
0
0

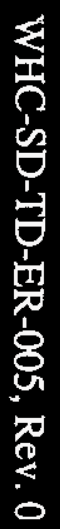


provides two separate work areas: the operating area contains the control panels and workstations that control the LDUA System; the visitor area has desks, shelves, data access workstations, and other amenities for people who are involved in analyzing data or planning the next activity. Overhead lighting is divided into several zones that are provided with separate dimmer controls.

The OCT is connected to the At-Tank Instrument Enclosure (ATIE) by the Fiber Optic Umbilical Cable. All control and data signals to and from the OCT pass through this cable over its many individual glass fibers ( 62.5 micron, multi-mode). Each subsystem has the exclusive use of two or more individual fibers to communicate between its equipment in the OCT and the ATIE. The Fiber Optic Umbilical Cable is small, lightweight, and rugged. It is impervious to electromagnetic interference and does not have to be electrically grounded for safety. It is capable of carrying signals over a much longer distance than the required $275 \mathrm{~m}(900 \mathrm{ft})$. The OCT provides an entrance penetration for the cable that is sealed with a flexible drawstring boot to keep out dust, insects, and rodents. This penetration emerges inside the trailer in an interface panel that contains a fiber optic connector panel which receives the connectors which terminate the individual fibers.

\subsubsection{Control and Data Acquisition System (4200)}

The LDUA System is controlled by a computer based system that distributes control of the individual subsystems to dedicated low-level controllers while providing a high-level supervisory control and data acquisition system that directs and coordinates the low-level controllers and provides an interface for the operators. Each subsystem has its own low-level controller that can support all its fundamental operations. This controller can be simple or sophisticated, according to the nature of the subsystem.

The supervisory controller is divided into the Supervisory Data Acquisition System (SDAS), which is responsible for controlling end effectors, and Supervisory Control System (SCS), which is responsible for controlling the LDUA and its deployment systems.

The LDUA system is designed to be operated remotely by two operators in the Operations Control Trailer using computer workstations. The LDUA operator is responsible for operating the deployment subsystems (VPM, LDUA, MDS, etc.), and the end effector operator is responsible for operating the end effectors and collecting data. A safety feature (point-ofcontrol) of the control system prevents simultaneous control from the Operations Control Trailer and local panels.

The LDUA Console operates the LDUA, VPM, and MDS. It provides display and access to the detailed status and operating parameters of the LDUA Subsystem controller (reference section 2.2.4). Hand controllers (joysticks) are connected to the LDUA Console for teleoperation of the VPM and LDUA.

The Operations Workstation operates in conjunction with the LDUA Console. It provides a 3-D animated graphic display for visualizing and previewing the motion of the VPM and LDUA in the environment of the tank. Motion of the VPM and LDUA can be simulated using any of the motion control modes (teleoperation, autosequences, joint mode, Cartesian 
mode, etc.) that the LDUA Controller provides. This simulated motion can be used as a preview to check for collisions between the LDUA and the tank structures or waste surface. The LDUA Controller remembers the most recent preview, and the operator can direct it to actually execute the previewed motion.

The Data Acquisition Workstation provides the primary user interface for operating end effectors, collecting data, and for monitoring and controlling the TRIC environment subsystems. It provides a single point from which data can be acquired, processed, and stored.

There are many video cameras in the LDUA System, including units on the LDUA, in end effectors, and in the ancillary equipment. The video display and recording subsystem provides video monitors and VCRs to display and record pictures from these cameras. All aspects of video switching and display and recording are controlled by the Data Acquisition Workstation, including the video cameras, the routing of signals, the VCRS, and the overlay of titles and other selected information onto the video.

The Auxiliary Workstation provides the ability to obtain information from the system without disturbing the operators at the primary workstations. It is located in the rear area of the Operations Control Trailer away from the operating area. Printers, plotters, and other peripheral devices are also located in this area.

A control pendant is attached by a $9 \mathrm{~m}$ (30ft) tether to the MDS and provides limited local control of the LDUA System. It is normally used to raise and lower the VPM housing and for gross positioning of the X-Y-Roll Table to align the VPM housing to the TRIC for attachment. The pendant can also be used during maintenance to jog each axes of the LDUA, VPM, and MDS.

\subsubsection{At-Tank Instrument Enclosure (4300)}

The At-Tank Instrument Enclosure houses the support electronics for the end effectors that must be near the end effector - the ATIE is located within $15 \mathrm{~m}$ (50ft) of the LDUA. This enclosure is weather tight with heating and cooling to maintain internal temperature between 50 and 95 degrees Fahrenheit during operation (see Figure 2-6). Standard Electronic Industrial Association (ELA) $48 \mathrm{~cm}$ (19in) racks are provided for mounting of end effector support equipment. Standard $110 \mathrm{VAC}$ power is provided for equipment.

All LDUA mounted end effectors share the common set of service utilities provided at the TIP. A patch panel in the ATIE allows them to be manually switched to the appropriate support electronics when a particular end effector is mounted on the TIP.

\subsubsection{Control Network (4400)}

The LDUA Supervisory Control and Data Acquisition System is computer based, with several workstations and embedded CPUs that intercommunicate. The Control Network provides a common network for all subsystems to use for this purpose. It provides an 10Base T twisted pair Ethernet connection for each computer. The backbone of this network is a 
WHC-SD-TD-ER-005, Rev. 0

Figure 2-6. At-Tank Instrument Enclosure (ATIE).

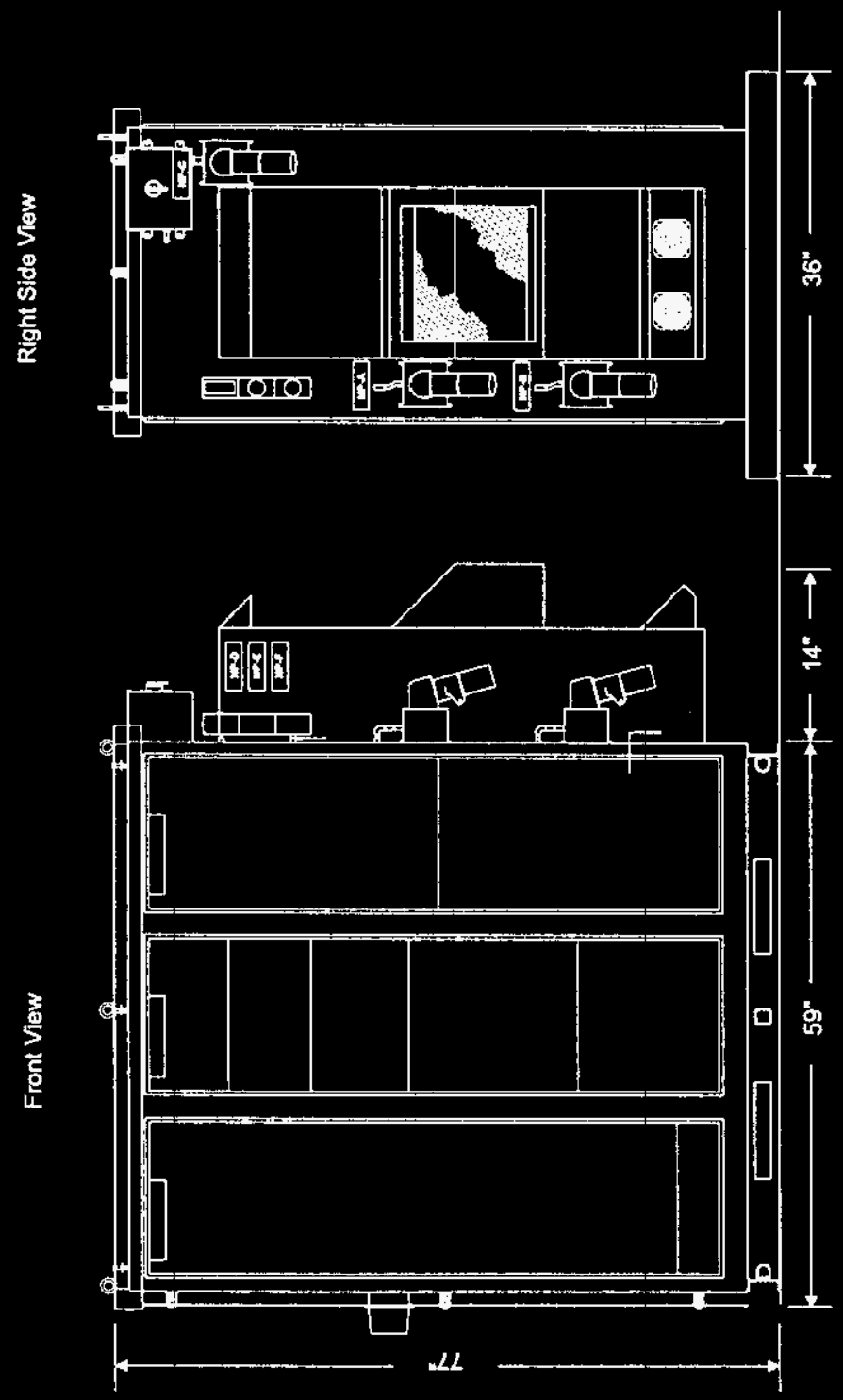


twenty-four port hub in the Operations Control Trailer. The Control Network uses standard Hanford Local Area Network (HLAN) components wherever possible so that maintenance and troubleshooting can be accomplished by Hanford network maintenance forces. The Control Network uses standard Category 5 twisted pair wiring which will support the current 10 megabit network and can be upgraded to a 100 megabit network if the extra bandwidth is required. At present, network connections from the ATIE are run from each CPU individually via pairs of fibers in the Fiber Optic Umbilical cable. If necessary to accommodate future growth, another hub could be added in the ATIE to route all its CPU network connections over a single pair of fibers. The hub is intelligent and may be assigned its own network address enabling it to be remotely monitored by Hanford network technicians. While the Operations Control Trailer is located in the Cold Test Facility, the hub is attached to HLAN. When the trailer is placed in the field, it may be operated as a stand alone network or reconnected to HLAN to provide site wide access to LDUA data.

\section{$2.5 \quad$ UTILITIES (5000)}

\subsubsection{Electrical Systems (5100)}

The LDUA System is powered from a 480 VAC, three phase power supply and it requires approximately $175 \mathrm{KVA}$. This power supply can be either a portable generator $(5120)$ or a temporary substation (5110) at the tank farm. The power source feeds the Operations Control Trailer (OCT) (4100) and the Power Distribution Skid (PDS) (5130). The PDS, which is placed inside the tank farm near the other LDUA equipment, converts the $480 \mathrm{VAC}$ main supply power to $208 \mathrm{Y} / 120 \mathrm{VAC}$ for use by the LDUA at-tank equipment. Power is transmitted into the tank farm at $480 \mathrm{VAC}$ to reduce the number and size of the power cables that must be handled. The PDS also provides circuit breakers and other protective features required by the National Electric Code (NEC). The power cables that connect to the PDS to the main power supply are physically bulky and heavy. They have been supplied in $30.5 \mathrm{~m}$ (100ft) and $61 \mathrm{~m}$ (200ft) sections that are more easily handled. The sections are provided with connectors that allow them to be hooked together to as needed.

\subsubsection{Compressed Gas Systems (5200)}

The Purge Air Supply System (5230) supplies instrument quality air for use by the LDUA purge system and for light use by end effectors with pneumatic devices. This purge air supply system is designed for outdoor use and has wheels and a handle for easy portability. The unit features a 15 gallon (minimum) ASME coded receiver with a continuous duty, oil-less compressor that supplies at least $142 \mathrm{~L} / \mathrm{min}(5.0 \mathrm{SCFM})$ air at $552 \mathrm{kPa}(80 \mathrm{psi})$ to $689 \mathrm{kPa}(100 \mathrm{psi})$. The LDUA purge system requires a nominal $71 \mathrm{~L} / \mathrm{min}(2.5 \mathrm{SCFM})$. Filters remove particles of 0.5 micron or larger and an air drier reduces the dew point to $-40 \mathrm{C}(-40 \mathrm{~F})$ or lower. Pressure differentials across filters and driers can be locally monitored, and the air delivery pressure can be locally monitored and controlled. A $15.2 \mathrm{~m}$ (50ft) long power cord is used to furnish electrical power to the compressor motor. A $7.6 \mathrm{~m}$ (25ft) long air supply hose is used for attachment to the purge inlet of the LDUA using color coded, keyed, double end shut-off quick connects to assure proper connections. A check valve at the end of the air supply hose prevents any potentially contaminated air from flowing back from the LDUA when the system is depressurized. 


\subsubsection{Miscellaneous Gas Systems (5400)}

The end effectors that are independently deployed in $10.2 \mathrm{~cm}$ (4in) risers will accept purge gas that is supplied from nitrogen bottles. Some of these end effectors have their own air compressors that can supply purge air.

\subsection{END EFFECTORS (6000)}

End effectors are the tools that accomplish the specific in-tank tasks that the LDUA System performs. There are two types of end effectors, LDUA deploved end effectors and independently deployed end effectors. LDUA deployed end effectors are TIP mounted on the end of the LDUA. Independently deployed end effectors enter the tank through other risers, usually $10.2 \mathrm{~cm}(4 \mathrm{in})$ risers, and provide their own riser interface equipment.

The LDUA Baseline System is supplied with a set of end effectors that provides a basic capability to deploy the system and to perform visual surveys and inspections of the tanks. This basic set of end effectors is described in this section. The LDUA Baseline System is designed to be extended to accommodate a wide variety of end effectors that can perform different in-tank tasks such as in-situ waste analysis, non-destructive examination of the tank structures, and small scale retrieval operations. These future end effectors are considered outside the scope of the LDUA Baseline System and are not described in this document. The document, WHC-SD-TDCR-001, Design Criteria For The Light Duty Utility Arm System End Effectors, (reference 2) provides the basic requirements which these future end effectors must meet in order to integrate with the LDUA System.

All end effectors are provided with storage and transportation containers.

\subsubsection{Tank Mapping Systems (6100)}

The Topographical Mapping System (TMS) (6110) uses laser light to accurately measure the interior surfaces of the tank structures and waste. Measurements are taken on a rectangular grid by an automatic scanning process. Contour maps of the scanned surface are generated. The TMS is an independently deployed end effector. The TMS has its own on-board computer and is completely autonomous. It communicates with the Supervisory Data Acquisition System (SDAS) using the Control Network to which it connects via a fiber optic link to the At-Tank Instrument Enclosure (ATIE). The operator controls the TMS via a control screen on the Data Acquisition Workstation. It is commanded to make a scan, or series of scans, and the finished surface map data is placed in data files that can be incorporated into the 3D model of the tank that is displayed on the Operations Workstation (see section 2.4.2).

\subsubsection{Remote Viewing Systems (6200)}

The LDUA Baseline System includes five video and photographic subsystems for remote viewing. Two of these subsystems are independently deployed end effectors and the other three are LDUA deployed end effectors. 
All five Remote Viewing System subsystems share a number of common features and components. All five provide self-contained lighting (using multiple $12 \mathrm{VDC} 35$ watt halogen reflector bulbs). All control and sensor channels for the end effectors are multiplexed onto the video signal to reduce the number of remote circuits needed. All five subsystems communicate between At-Tank Instrumentation Enclosure and the Operations Control Trailer using the fiber-optic umbilical. All the subsystems provide a similar interface with the Supervisory Data Acquisition System (SDAS) in the OCT using individual VME card V/O channels. Each channel directly controls or monitors one camera function such as pan, tilt, zoom, focus, lighting, or position. The three LDUA deployed end effectors that are carried on the LDUA share a single set of support electronics since not more than one can be operated at a time. Mechanically, they are designed to withstand the tank environment which includes the ability to operate in a Class 1 , Division 1, Group B flammable atmosphere (all are purged).

2.6.2.1 The Overview Video System (OVS) (6210). OVS is an independently deployed end effector designed to provide general observation of in-tank activities and to provide visual feedback to the operator (see Figure 2-7). If necessary, it can go into the tank before any other equipment to provide a "first look" at the tank internals. The OVS at-tank unit is contained in a rectangular housing supported off the ground by four adjustable feet. It is designed to be placed over the deployment riser and connected to it by a flexible seal that maintains containment of the tank atmosphere and airborne contamination. The OVS camera head is cylindrical with a maximum diameter of $8.9 \mathrm{~cm}(3.5 \mathrm{in})$ and is deployed into the tank on the end of a sealed flexible conduit which is raised and lowered by means of a motorized cable reel. When fully retracted, the camera head is completely contained in the housing, allowing the unit to be easily sealed for transport to another riser. In addition to supporting the camera. head, the flexible conduit also carries the electrical services and purge air for it (purge air is normally supplied by an on-board compressor or bottled nitrogen can be externally supplied). The electrical services are connected to the cable reel through a coupling which accommodates the rotation of the reel without using slip rings, which historically have been a concern for reliability and maintenance.

The OVS camera unit provides a fully radiation hardened black and white camera and 4:1 zoom lens (see Figure 2-8). The camera is located at the bottom of the cylindrical housing looking downward. A remotely controlled tilting mirror (metal, first surface) changes the camera's viewing angle without moving the camera. The camera housing rotates about the vertical axis to pan the camera view. Because no part of the camera housing ever extends outside the cylindrical envelope, the OVS can always be recovered from the tank and riser under any failure conditions.

2.6.2.2 The Overview Stereo Video System (OSVS) (6220). OSVS is virtually identical to the OVS system, including all of the same deployment and control features, except that it provides a pair of color video cameras that are aligned and spaced to produce a stereoscopic video image that provides the operator with depth perception. Remote adjustments to camera separation are provided along with multiple lenses of different magnification. Magnification step changes are a preferred solution to zoom lenses for stereo applications because is it difficult to synchronize zoom lenses. The current state of the art does not provide suitable radiation hardened color cameras, but radiation tolerant chip cameras are available and are used in this system. The two separate video signals from the cameras are combined into a stereo image by equipment in the 
WHC-SD-TD-ER-005, Rev. 0

OCT that is part of the SDAS Video Display and Recording System. The operator is provided with special glasses in order to observe the stereo image.

2.6.2.3 The High Resolution Stereo Video System (HRSVS) (6230). HRSVS is an LDUA deployed end effector that provides a magnified image for inspecting suspect features on the tank structure or in the waste. A special lens system is provided to allow constant size viewing from an adjustable standoff distance. This system has a pair of color video cameras that provide a stereoscopic image in the same fashion was the OSVS (Figure 2-8). 
WHC-SD-TD-ER-005, Rev. 0

Figure 2-7. Overview Video System (OVS).

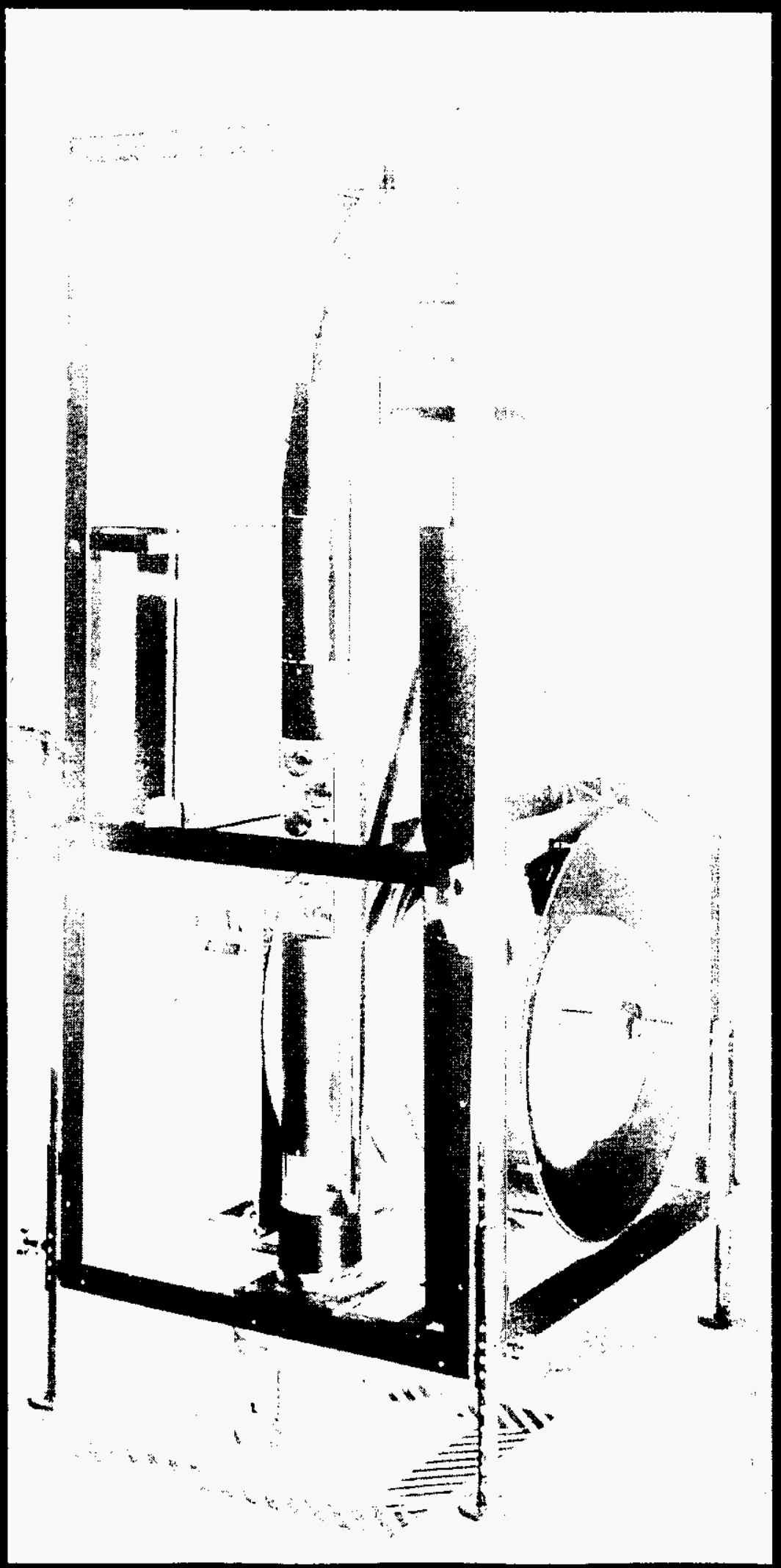


WHC-SD-TD-ER-005, Rev. 0

Figure 2-8. Overview Video System

Camera

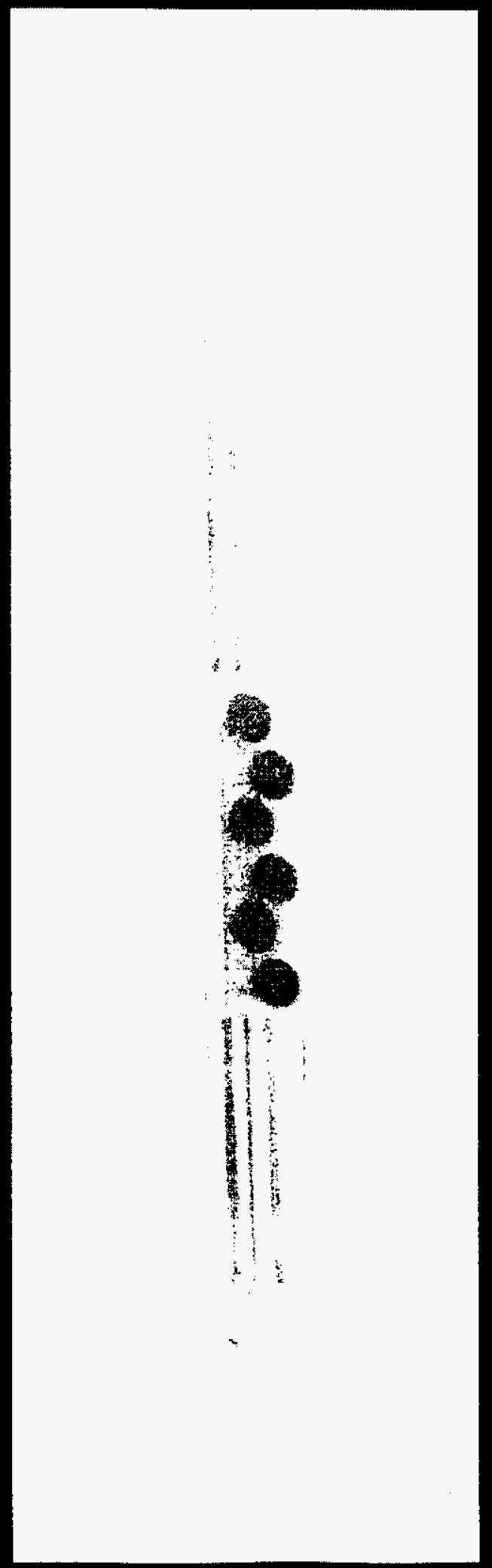


WHC-SD-TD-ER-005, Rev. 0

Figure 2-9. High Resolution Stereo Video System (HRSVS).

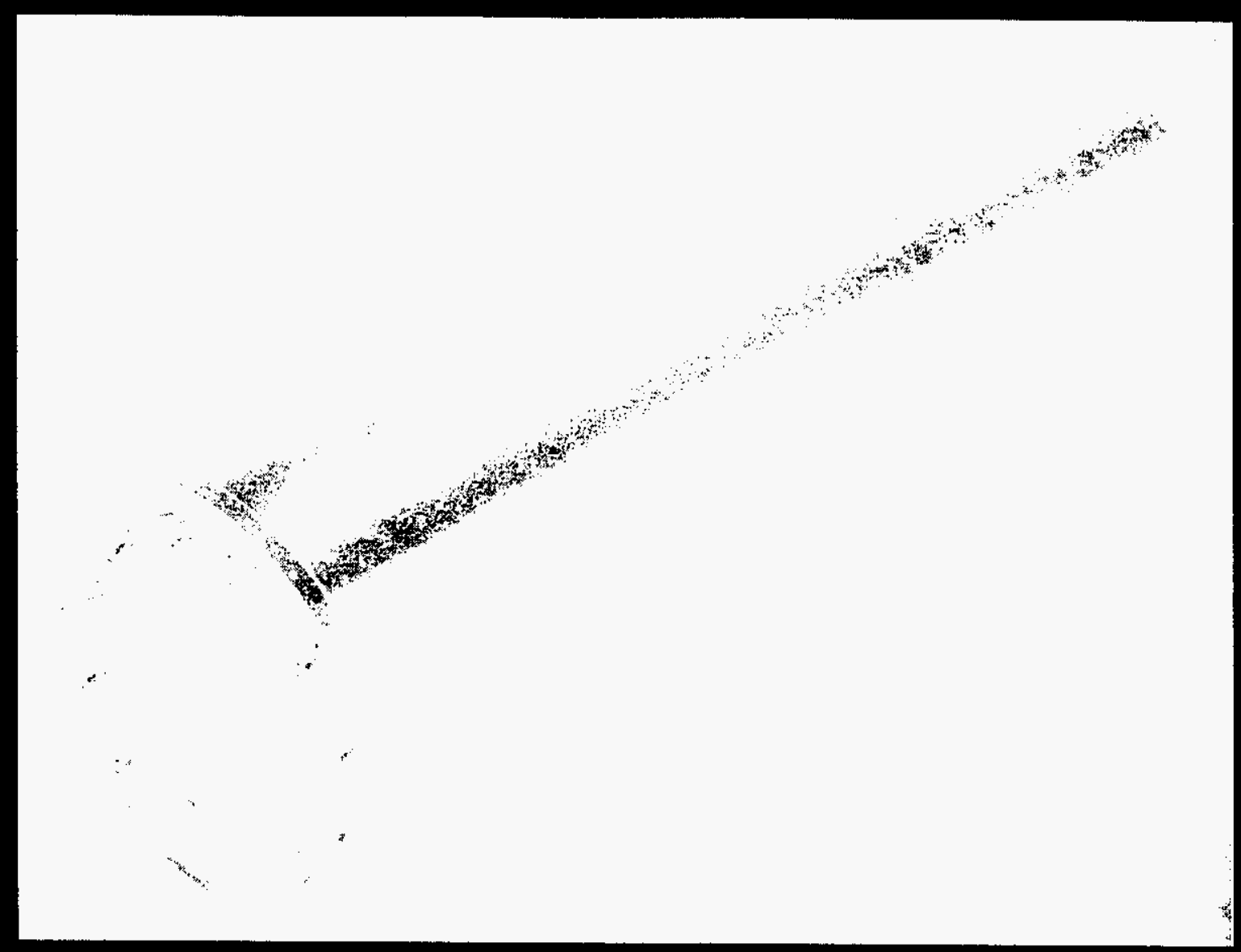


2.6.2.4 The Still/Stereo Photo System (SSPS) (6240). SSPS is an LDUA deployed end effector that provides a pair of $35 \mathrm{~mm}$ single lens reflex film cameras for making stereo photographic images for off line analysis (film provides at least ten times more resolution than the best video cameras). The film cameras have been modified to be remotely controlled. A video camera is coupled to the viewfinder of each film camera to assist the operator in composing the photo and aiming the camera. Two synchronized photo flash units are provided.

2.6.2.5 The Optical Alignment Scope (OAS) (6250). OAS is an LDUA deployed end effector that is used for aligning the Vertical Positioning Mast to the deployment riser. It uses a boresighting technique that is augmented by two kinds of laser systems. A video camera is placed in the end effector so as to be accurately aligned with the centerline of motion of the VPM. This camera will look down into the riser. The alignment process will begin with the VPM only slightly deployed to place the end effector in the TRIC above the riser. The operator will move the translational and rotational axes of the X-Y-Roll Table until the images of the lower rim and upper rim of the riser are concentric and centered in the camera reticle. One of the laser systems is intended to assist the operator by projecting four intersecting lines on the inside of the riser in a pattern resembling a tic-tac-toe grid. The other laser system is intended to be used once a boresighted condition has been achieved in order to verify that the LDUA equipment will not hit the riser wall. This system projects four narrow beams of laser light down into the riser that are accurately aligned in the same direction as the VPM motion, but that are placed slightly outside the maximum diameter of the VPM. Proper alignment of the VPM housing is verified when none of the beams touches the riser wall as the end effector is slowly rotated through 90 degrees. The OAS also has proximity sensors that measure the clearance with the inner wall of the riser as the OAS is lowered through the riser in the final alignment confirmation process. Although the OAS is fully qualified for the in-tank environment in all other respects, several of its components are not radiation hardened because it is not intended to be used inside the tank.

\subsection{COLD TEST FACILITY (7000)}

The Cold Test Facility (CTF) has historically been considered part of the LDUA System even though it is a fixed facility and is not part of the equipment that is deployed in the tank farms (Figure 2-10). This is because the CTF is required to support the full systems testing that is necessary to qualify the LDUA System for deployment. A special facility is needed because it must provide at least $13.7 \mathrm{~m}(45 \mathrm{ft})$ of clearance above ground level and a test area that reaches at least $9.1 \mathrm{~m}$ (30ft) below ground level with enough room to exercise the LDUA. A portion of Building 427, the Fuels and Materials Examination Facility (FMEF), was chosen to be the CTF in 1993 because it satisfies these critical conditions. The selection criteria and process are documented in WHC-SD-TD-ES-003, Light Duty Utility Arm Cold Test Facility Engineering Study (reference 3). Various pieces of test support equipment, such as simulated tank risers, have been installed in the FMEF. 
Figure 2-10. LDUA Cold Test Facility (CTF).

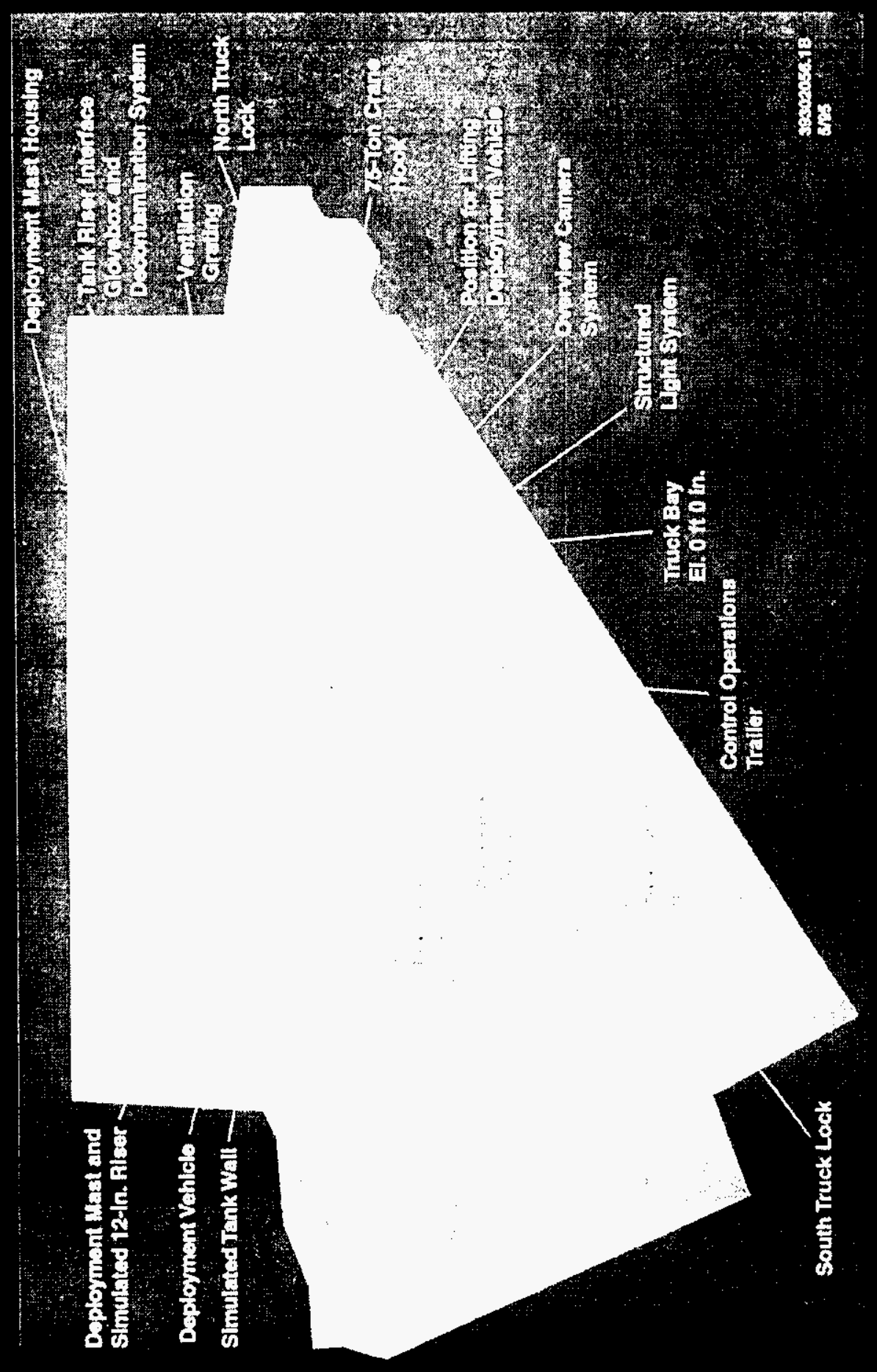


WHC-SD-TD-ER-005, Rev. 0

\subsection{OTHER EQUIPMENT (8000)}

\subsubsection{Riser Characterization Equipment (8100)}

Plug gages are used for verifying that there is a sufficiently clear path through a riser for LDUA equipment to pass without binding. There is a plug gage for $10.2 \mathrm{~cm}$ (4in) risers that is $9.20 \mathrm{~cm}$ ( $3.625 \mathrm{in})$ outside diameter and one for $30.5 \mathrm{~cm}(12 \mathrm{in})$ risers that is $26.99 \mathrm{~cm}(10.625 \mathrm{in})$ outside diameter. The plug gages are designed to be lowered into the risers by crane. They are each provided with water spray nozzles at the bottom end that are used to spray the inside of the riser in order to reduce the potential for contamination.

\subsubsection{Operations Overview Video System (8200)}

The Operations Overview Video System provides the operators inside the Operations Control Trailer (OCT) with a means of viewing activities within the tank farm. This system has a video camera equipped with a zoom lens and a pan/tilt mounting that is set up outside the tank farm perimeter fence near the trailer. The operators can control the camera and can display its output on their video monitors inside the OCT. 


\subsection{OPERATING SCENARIO}

This section describes the nominal sequence of operations for a typical LDUA campaign at a single tank. An equipment arrangement for a typical deployment is shown in Figure 3-1.

\subsection{LDUA SYSTEM SETUP}

When a tank has been identified for inspection, plug gages will be used to verify that the risers chosen for deployment are adequately plumb and have adequate internal clearance for the LDUA deployed and independently deployed end effectors.

Following successful riser gaging, the major equipment systems of the LDUA System will be transported to the tank farm and set up. The Operations Control Trailer (OCT) will be placed outside the tank farm fence. The At-Tank Instrument Enclosure (ATIE) will be placed in the vicinity of the riser chosen for LDUA deployment. The Fiber Optic (FO) Umbilical Cable will be connected between the ATIE and the OCT. The Power Distribution Skid (PDS) will be placed inside the tank farm near the other equipment and power cables will be connected between it and the main source of $480 \mathrm{VAC}$ (either a portable generator or a temporary substation). Power cables will also be connected between the PDS and the ATIE, and between the OCT and the main power source.

Independently deployed end effector systems will be attached to the risers chosen for their deployment. These systems will have their own riser interface and environmental containment and any necessary local support electronics. They will be connected to the ATE and will be operated from the OCT.

The Tank Riser Interface and Confinement (TRIC) subsystem will be attached to the riser chosen for deployment of the LDUA. This installation process will be done in two steps. First, the riser isolation valve will be attached to the tank riser. Then the rest of the TRIC will be attached to the riser isolation valve by a quick-disconnect joint. The TRIC's decontamination module will be connected to the Decon Water Supply System. During LDUA operations, the Riser Isolation Valve will be manually operated, as circumstances require, to provide access to the tank or to isolate the tank atmosphere from the TRIC.

The LDUA system will be transported to the tank using the Mobile Deployment System (MDS). The MDS will be positioned near the TRIC with the help of a guide fixture to assure that the VPM will be properly aligned to the TRIC when it is elevated. The MDS will be connected to the Power Distribution Skid so that its hydraulics can be powered up. The MDS outriggers will be extended and locked to provide a firm base for LDUA deployment. Load pads will provided for the outriggers to match the soil and surface conditions. The control pendant attached to the MDS will be used to upend, position, and align the Vertical Positioning Mast (VPM) housing to mate with the TRIC. A contamination control boundary will be established 


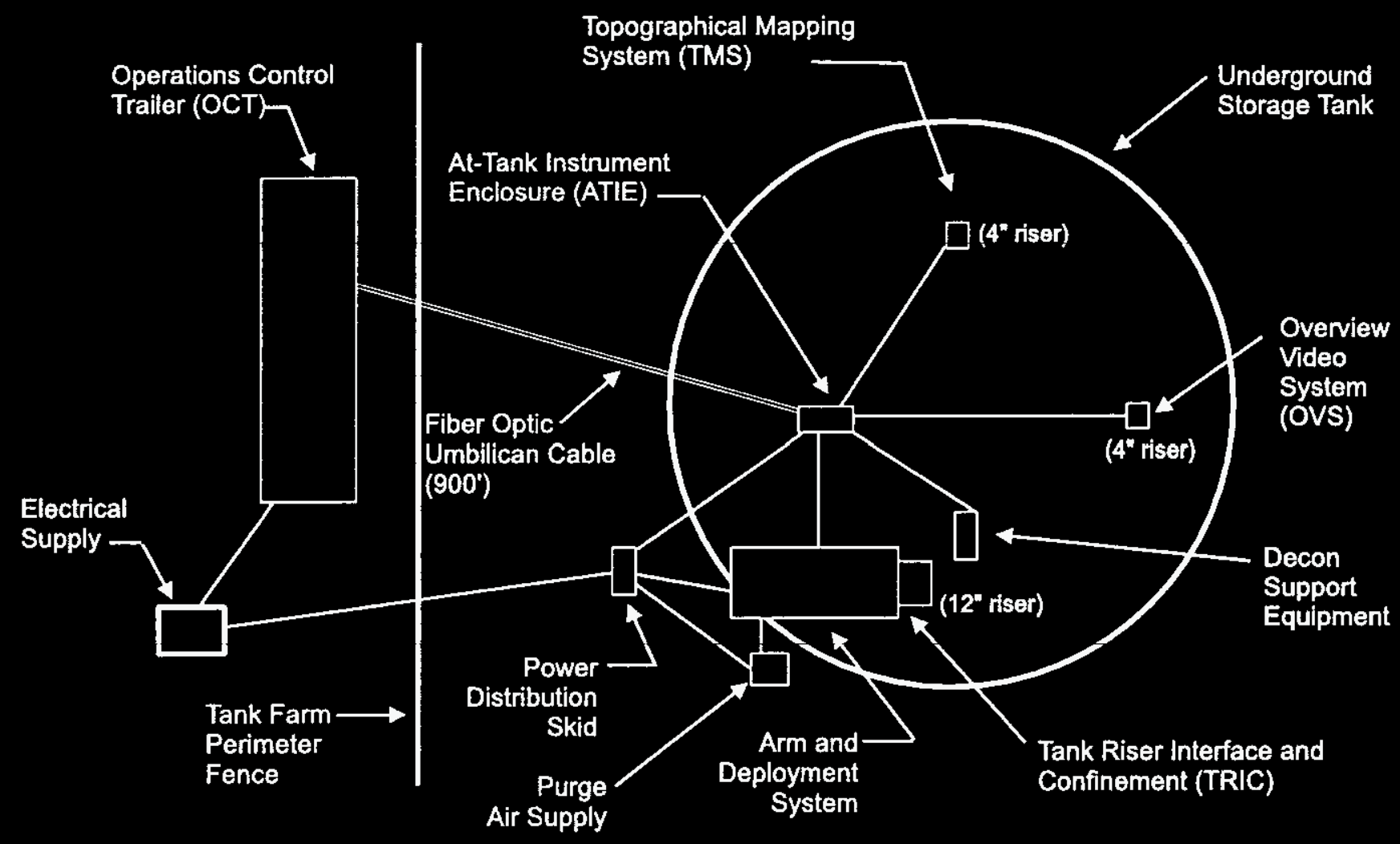

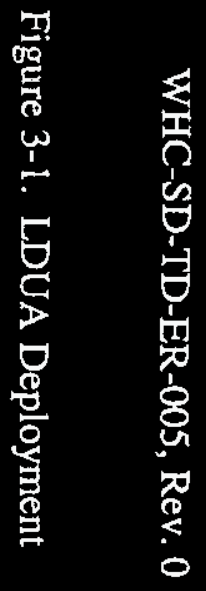


between the TRIC and the VPM housing using the flexible mast housing adapter. The tank pressure sense line for the purge system will be connected between the TRIC and the MDS. With the mating to the TRIC complete, the MDS umbilical will be connected to the ATIE and full control will be transferred to the LDUA Console and Supervisory Control System (SCS) inside the OCT. The Optical Alignment Scope (OAS) end effector will be used to finalize the position of the VPM housing to insure that the VPM and LDUA are accurately aligned with the riser to provide a clear path for entering the tank.

\subsection{LDUA SYSTEM OPERATION}

To initiate a surveillance, inspection, or characterization campaign, an end-effector will be selected for the desired operation. The installation of the end effector to the LDUA will be accomplished within the TRIC, utilizing a tool exchange mechanism to assist the operator in positioning the end effector and attaching it to the LDUA. Following end effector attachment, the VPM, LDUA, and end effector will be lowered through the TRIC and the decontamination system and into the tank through the tank riser. These operations will usually be performed from the OCT; however, the MDS control pendant can provide simple operation of LDUA and VPM for recovery or maintenance activities.

Operation of the LDUA and end effectors inside the waste tank will normally be performed from the Operations Control Trailer using supervisory control (automated sequences) or by teleoperation (human in the loop) using graphic computer displays to monitor and control the equipment, and on-board and overview cameras to provide direct visual feedback to the operator. After lowering the VPM to the desired elevation in the tank, the LDUA will position end effectors to perform their in-tank functions. End effectors will normally be operated from the using the Supervisory Data Acquisition System, which will also collect the data they generate. It is anticipated that a typical campaign will last one to two weeks. During this period, multiple end effector exchanges may be performed without removing the VPM housing from the TRIC. Gross decontamination of the VPM, LDUA and end effectors will take place during these exchanges as the VPM is withdrawn through the decontamination module. It is expected that the LDUA and VPM will be retracted into the VPM housing during the off shift and will be moved to the area of lowest radiation level inside tank when not busy.

\subsection{LDUA SYSTEM TAKEDOWN}

When in-tank operations have been completed, the end effector will be dismounted from the LDUA and the VPM and LDUA will be retracted into the VPM housing. The VPM housing will be sealed to contain any residual contamination on the VPM and LDUA before it is detached from the TRIC. The VPM housing will then be lowered to the horizontal position on the MDS for storage and transport. The independently deployed end effector systems will be recovered from the tank and their equipment secured for transport. The TRIC will be removed from the riser and the riser will be closed. The umbilical and power cables between the Power Distribution Skid, the ATIE and the OCT will be disconnected and recovered, and the ATIE and OCT made ready for transport. 


\section{WHC-SD-TD-ER-005, Rev. 0}

\subsection{ROAERENCES}

1. WHC-SD-TD-FRD-003, Functions and Requirements for the Light Duty Utility Arm Integrated System, Westinghouse Hanford Co., Richland, Washington, 1994.

2. WHC-SD-TD-CR-001, Design Criteria For The Light Duty Utility Arm System End Effectors, Westinghouse Hanford Co., Richland, Washington, 1994, 1995.

3. WHC-SD-TD-ES-003, Light Duty Utility Arm Cold Test Facility Engineering Study, Westinghouse Hanford Co., Richland, Washington, 1994, 1995. 
WHC-SD-TD-ER-005, Rev. 0

\section{APPENDIX A LDUA SYSTEM BLOCK DIAGRAMS}

This appendix provides details about the design of the LDUA Baseline System in the form of block diagrams.

Figure A-1 is an overall block diagram of the LDUA Baseline System showing all the major equipment systems and subsystems and how they interconnect. Most of the system interconnections are electrical, either power or control, but there are some air and water lines as well.

Figure A-2 is a block diagram of the control and data acquisition system. Figure A-3 is a block diagram of the VME portion of the control and data acquisition system. Figure A-4 is a block diagram of the Video Display and Recording portion of the Supervisory Data Acquisition System (SDAS).

Figure A-5 is a block diagram of the software. It shows the major processes (tasks), what CPUs they execute one, and what information they communicate. 
WHC-SD-TD-ER-005, Rev 0

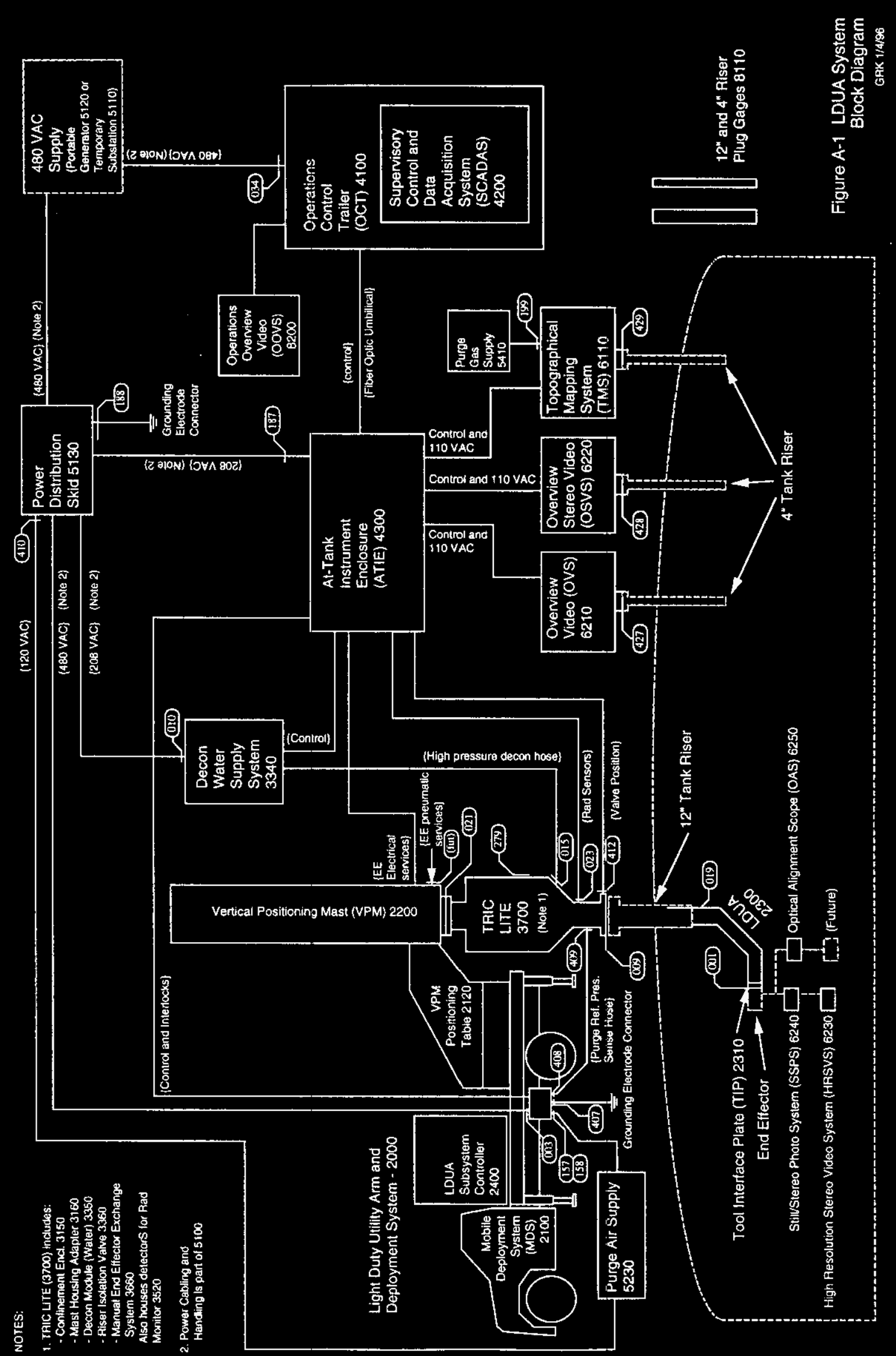

Figure A-1 LDUA System Block Diagram 


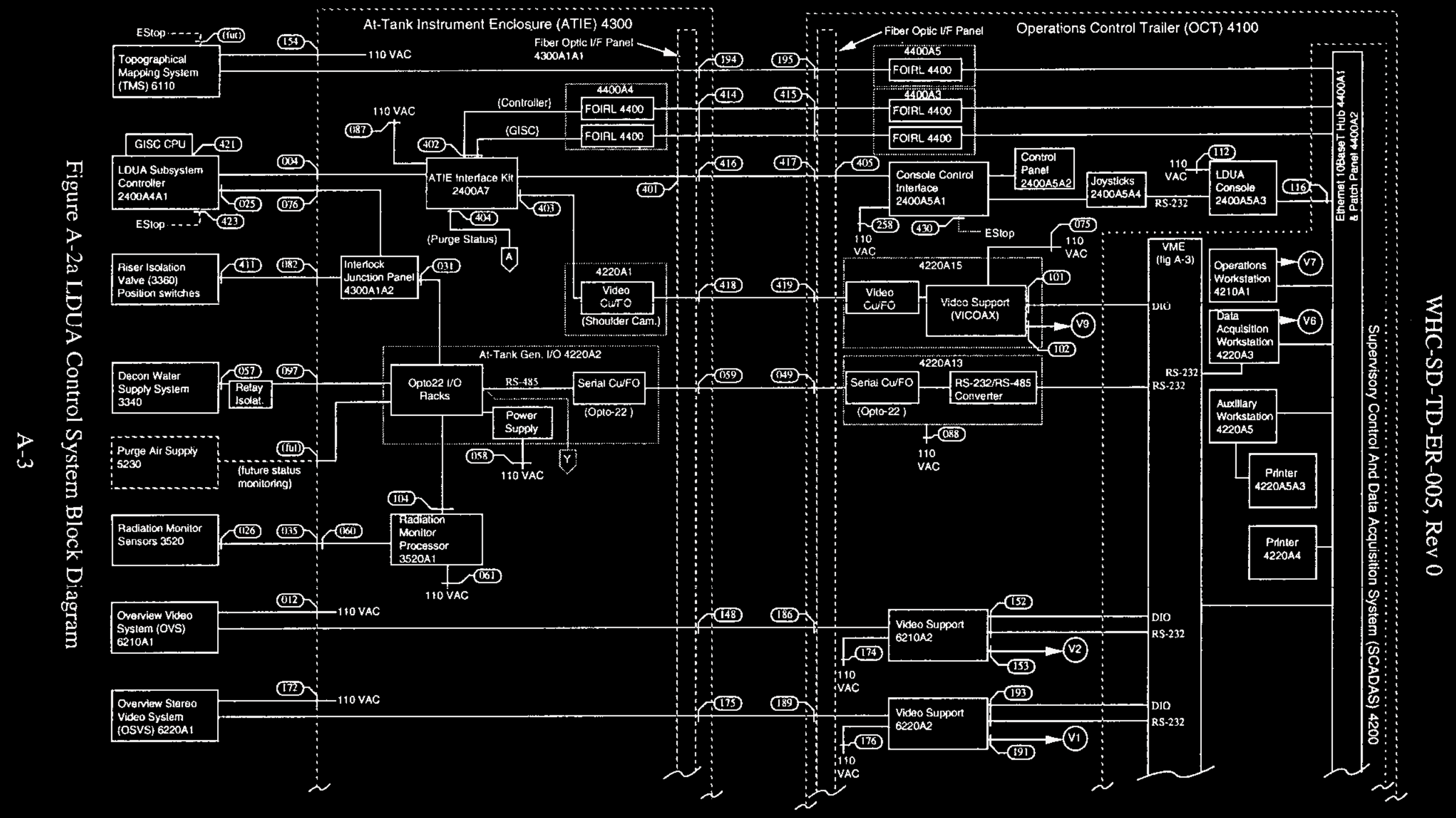


WHC-SD-TD-ER-005, Rev 0

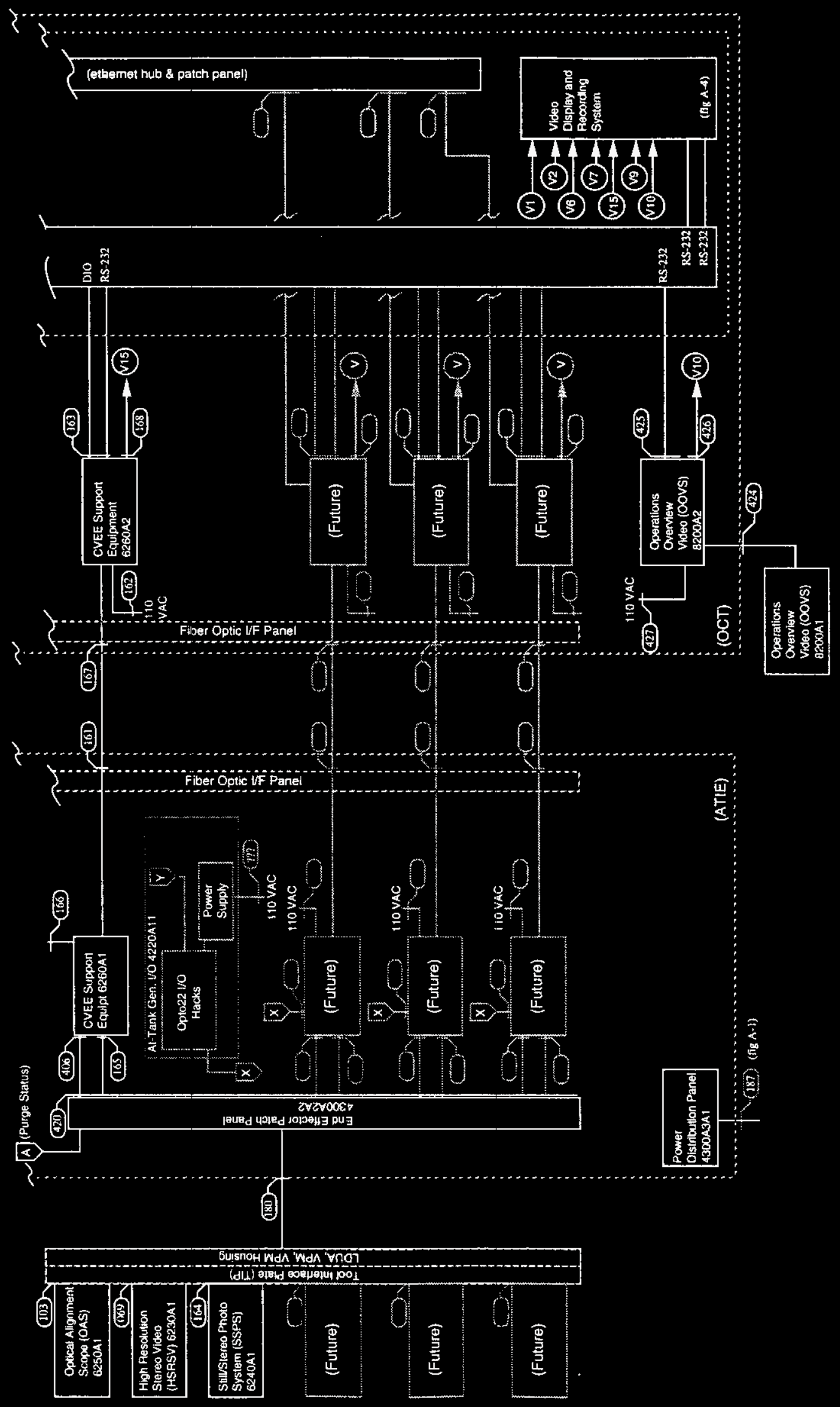

Figure A-2b LDUA Control System Block Diagram (cont.) 


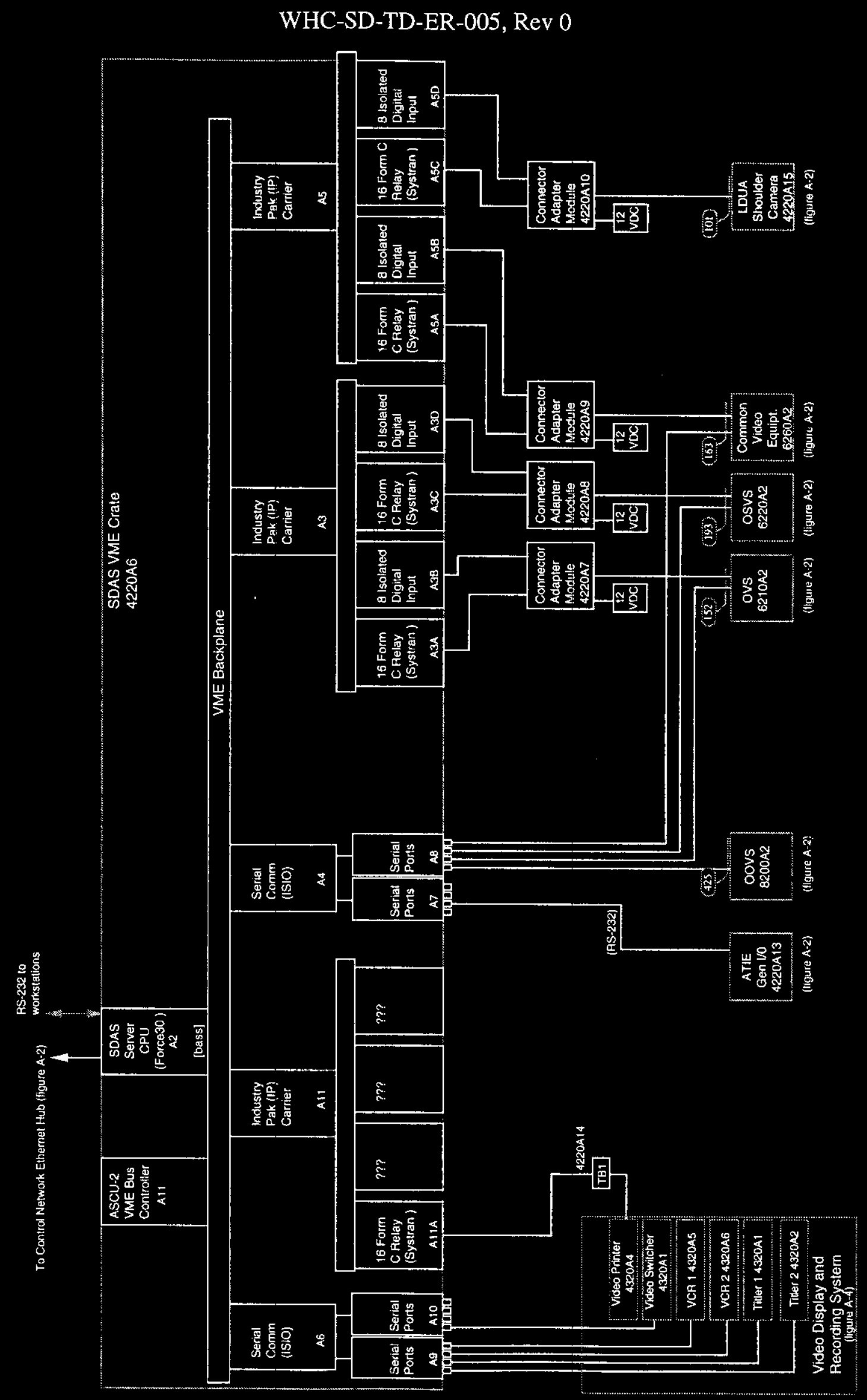

Figure A-3 LDUA VME Block Diagram 


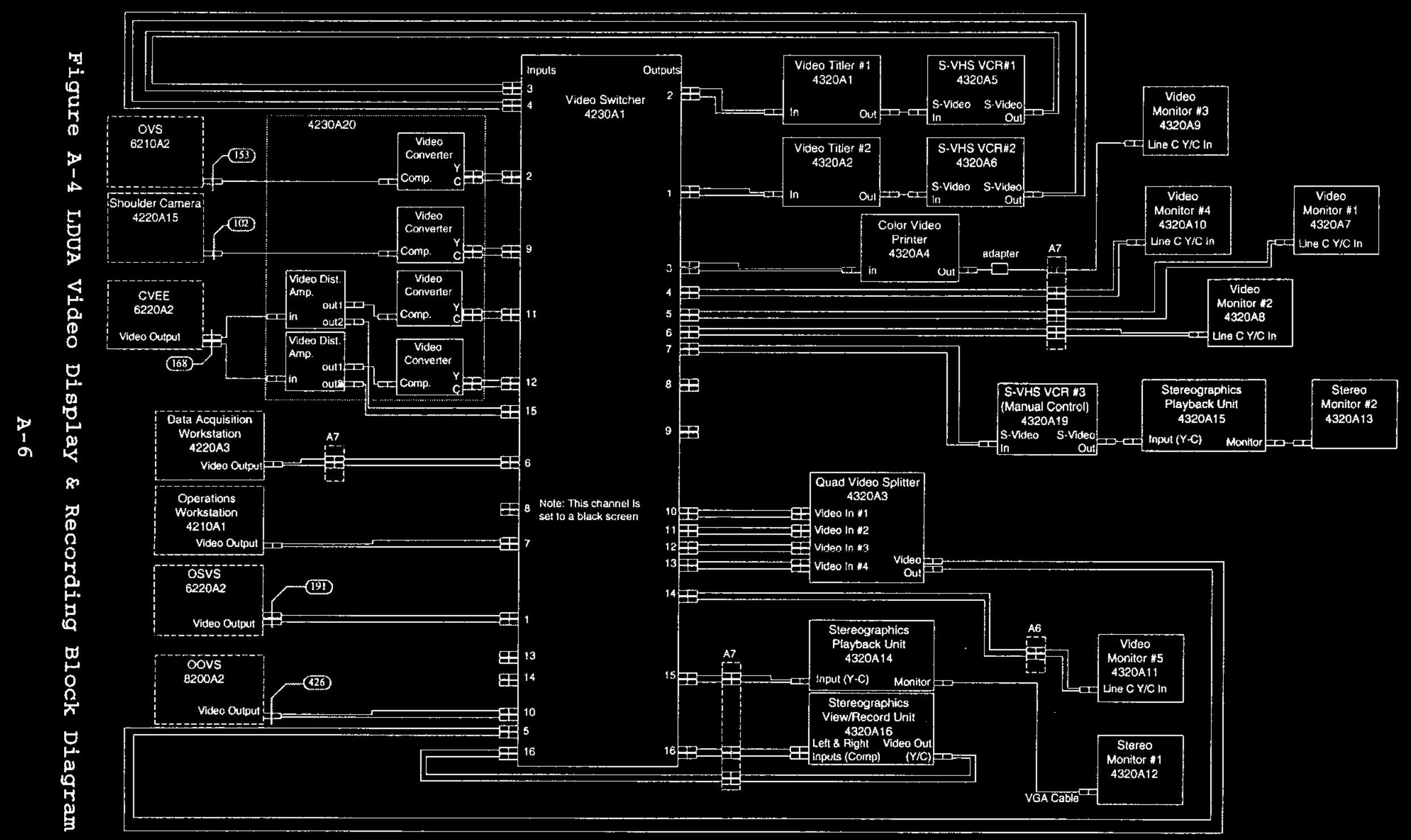




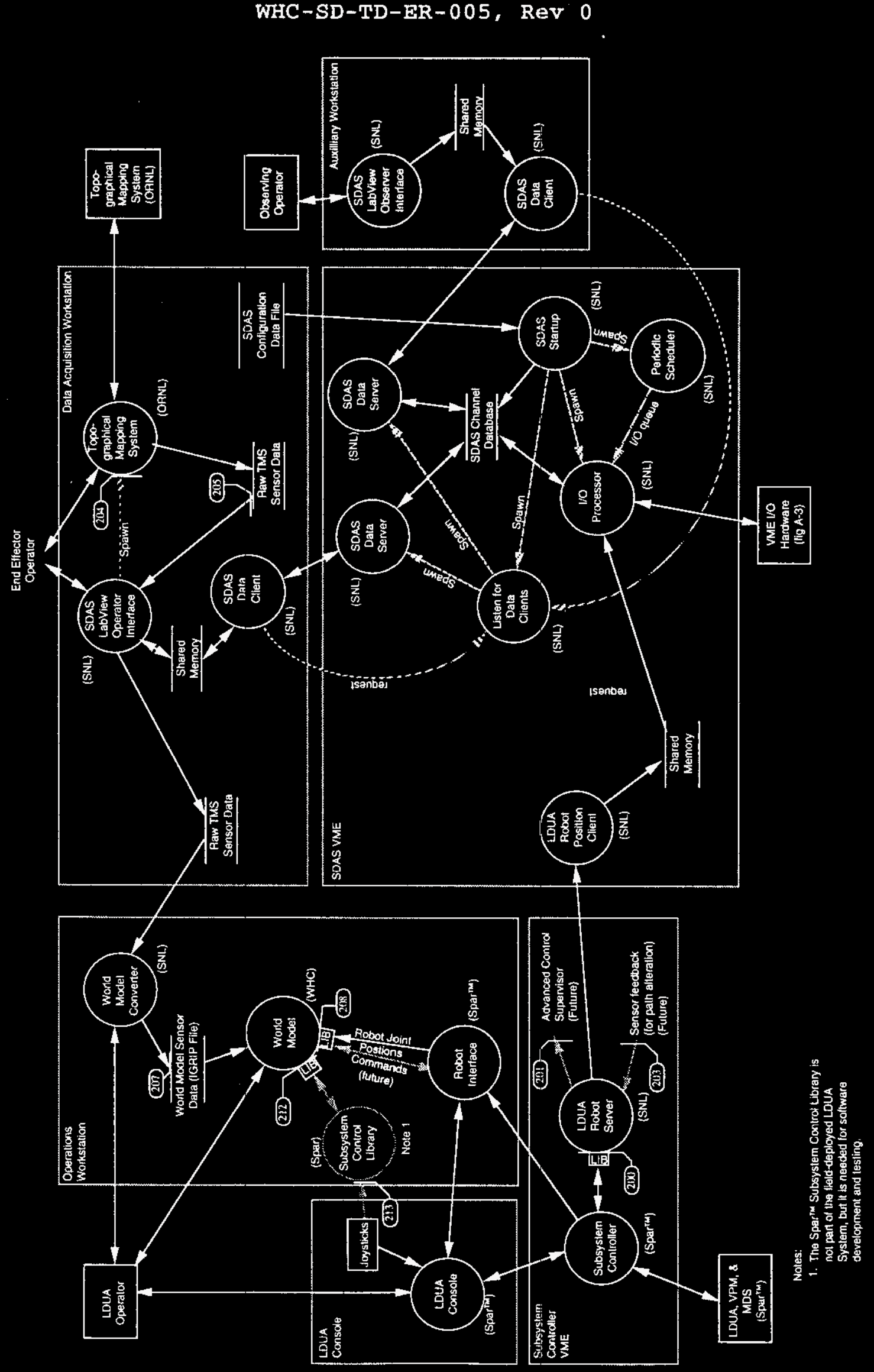

Figure A-5 LDUA Software Block Diagram

$$
\text { A-7 }
$$




\section{DISTRIBUTION SHEET}

\begin{tabular}{|c|c|c|c|c|c|}
\hline \multirow{2}{*}{$\begin{array}{l}\text { To } \\
\text { Distribution }\end{array}$} & \multirow{2}{*}{\multicolumn{3}{|c|}{$\begin{array}{l}\text { From } \\
\text { G. R. Kiebel }\end{array}$}} & \multicolumn{2}{|l|}{ Page 1 of 1} \\
\hline & & & & \multicolumn{2}{|c|}{ 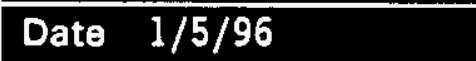 } \\
\hline \multirow{2}{*}{\multicolumn{4}{|c|}{$\begin{array}{l}\text { Project Title/Work Order } \\
\text { Light Duty Utility Arm } \\
\text { WHC-SD-TD-ER-005, "Light Duty Utility Arm Baseline System } \\
\text { Description" }\end{array}$}} & \multicolumn{2}{|c|}{ EDT No. 140941} \\
\hline & & & & \multicolumn{2}{|l|}{ ECN No. } \\
\hline Name & MSIN & $\begin{array}{c}\text { Text } \\
\text { With All } \\
\text { Attach. }\end{array}$ & Text Only & $\begin{array}{l}\text { Attach./ } \\
\text { Appendix } \\
\text { Only }\end{array}$ & $\begin{array}{c}\text { EDT/ECN } \\
\text { Only }\end{array}$ \\
\hline $\begin{array}{l}\text { B. A. Carteret } \\
\text { D. S. Dutt } \\
\text { G. R. Kiebel } \\
\text { LDUA Files (10) } \\
\text { Central Files (original }+1 \text { ) }\end{array}$ & $\begin{array}{l}N 1-21 \\
N 1-21 \\
N 1-21 \\
N 1-21 \\
A 3-89\end{array}$ & $\begin{array}{l}x \\
x \\
x \\
x \\
x \\
\end{array}$ & & & \\
\hline
\end{tabular}

